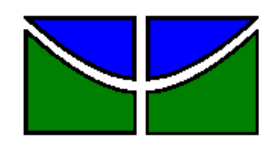

Universidade de Brasília

Faculdade de Economia, Administração e Contabilidade

Departamento de Administração

\author{
JULIANA QUEIRÓS MIRANDA
}

\title{
O Processo de Entrada e os Fatores de Consolidação da Empresa Francesa CNP Assurances no Mercado Brasileiro
}

Brasília - DF 


\section{JULIANA QUEIRÓS MIRANDA}

\section{O Processo de Entrada e os Fatores de Consolidação da Empresa Francesa CNP Assurances no Mercado Brasileiro}

Monografia apresentada ao

Departamento de Administração como requisito parcial à obtenção do título de Bacharel em Administração.

Professor Orientador: Doutora, Janann Joslin Medeiros

Brasília - DF 
Miranda, Juliana Queirós.

O Processo de Entrada e os Fatores de Consolidação da Empresa CNP Assurances no Mercado Brasileiro/ Juliana Queirós Miranda. - Brasília, 2-2010.

66 f. : il.

Monografia (bacharelado) - Universidade de Brasília, Departamento de Administração, 2011. Orientador: Prof. Dra. Janann Joslim Medeiros, Departamento de Administração.

1. Internacionalização de empresas. 2. Entrada de serviços financeiros. 3. Seguros 



\section{JULIANA QUEIRÓS MIRANDA}

\section{O Processo de Entrada e os Fatores de Consolidação da Empresa Francesa CNP Assurances no Mercado Brasileiro}

A Comissão Examinadora, abaixo identificada, aprova o Trabalho de Conclusão do Curso de Administração da Universidade de Brasília da aluna

\section{Juliana Queirós Miranda}

Doutora, Janann Joslin Medeiros

Professor-Orientador

Doutor, Valmir Emil Hoffman,

Professor-Examinador
Mestre, Osório Carvalho Dias

Professor-Examinador 
Dedico este trabalho aos meus pais, Paulo Miranda e IIma Queirós, a quem devo tudo que me tornei e minhas fontes de admiração e inspiração, às minhas irmãs, Sinara e Talita, pelo constante apoio e carinho, à minha segunda família, José, Lourdes, Danilo, Mariana e Carol, pela paciência e imensurável ajuda no dia-a-dia e, por fim, ao Bernardo, fonte de sorrisos e alegrias diárias. 


\section{AGRADECIMENTOS}

Agradeço a Deus pela vida e saúde, à professora Janann pelo conhecimento e dedicação ao realizar este trabalho, ao José Coelho pela ajuda para que este trabalho pudesse ser realizado. 
A maior de todas as ignorâncias é rejeitar uma coisa sobre a qual você nada sabe. (H. Jackson Brown, Jr.) 


\section{RESUMO}

O trabalho objetiva descrever o processo e identificar os fatores de entrada da empresa francesa CNP Assurances no Brasil. Para isso, descreveram-se os fatores brasileiros e franceses que contribuíram para tornar real esta entrada estrangeira, identificando os propulsores de expansão de uma empresa de país desenvolvido para um país em desenvolvimento, como e porque foi realizada a entrada com uma empresa pública brasileira. Considerou-se necessária a revisão das principais teorias de internacionalização, como é realizada a internacionalização de serviços e dos serviços financeiros e, por fim, as estratégias de internacionalização. Este estudo de caso deu-se mediante a realização de pesquisa qualitativa e descritiva, por meio de entrevista com um gestor brasileiro e outro francês, ambos envolvidos no processo de entrada no Brasil, e ainda, uma análise documental dos principais demonstrativos financeiros. Por meio da pesquisa foi possível apontar que os resultados com respeito ao modo de entrada e às razões corroboram os resultados de estudos anteriores sobre o tema neste setor de serviços.

Palavras-chave: 1. Internacionalização de empresas. 2. Internacionalização de serviços financeiros. 3. Seguros. 


\section{LISTA DE ILUSTRAÇÕES}

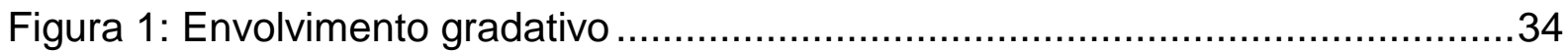

Figura 2: Organograma do Grupo CAIXA SEGUROS ....................................60

Figura 3: Faturamento do Mercado .......................................................60

Figura 4: Faturamento do Grupo Caixa Seguros...........................................61

Figura 5: Quantidade de produtos vendidos por canal ...................................61

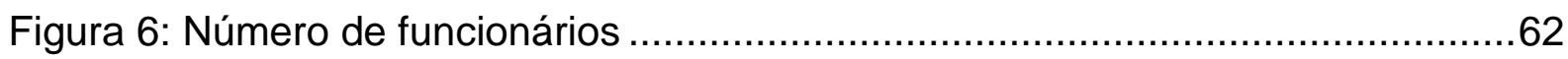

Figura 7: Despesa Administrativa do Grupo Caixa Seguros ...............................62

Figura 8: Margem técnica do Grupo Caixa Seguros ......................................63

Figura 9: Resultado financeiro do Grupo Caixa Seguros ..................................63

Figura 10: Despesas com impostos do Grupo Caixa Seguros .............................64

Figura 11: Resultado líquido do Grupo Caixa Seguros ....................................64

Figura 12: Retorno sobre o patrimônio líquido ..............................................65

Figura 13: Patrimônio líquido do Grupo Caixa Seguros ....................................65

Figura 14: Ativos sob gestão do Grupo Caixa Seguros.........................................66

Figura 16: Margem de solvência do Grupo Caixa Seguros .................................66

\section{LISTA DE QUADROS}

Quadro 1: Os determinantes da produção internacional em serviços auxiliares ......25

Quadro 2: prêmios e reconhecimento do grupo CAIXA SEGUROS .........................58 


\section{LISTA DE ABREVIATURAS E SIGLAS}

AEN - Área Estratégica do Negócio.

CEF - Caixa Econômica Federal.

CNSP - Conselho Nacional de Seguros Privados.

FENASEG - Federação Nacional das Empresas de Seguros Privados, Previdência e de Capitalização.

FUNCEF - Fundo dos Economiários Federais.

IED - Investimento Externo Direto.

PIB - Produto Interno Bruto.

SASSE - Serviço de Assistência Social e Seguros dos economiários.

SELIC - Sistema Especial de Liquidação e Custódia. 


\section{SUMÁRIO}

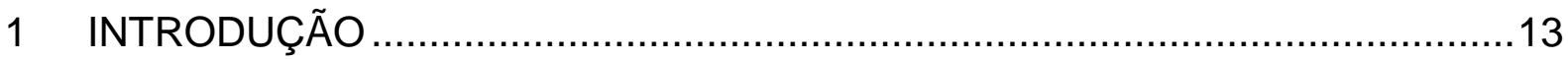

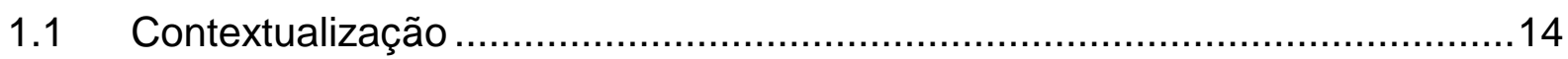

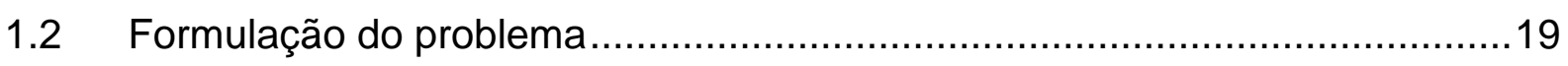

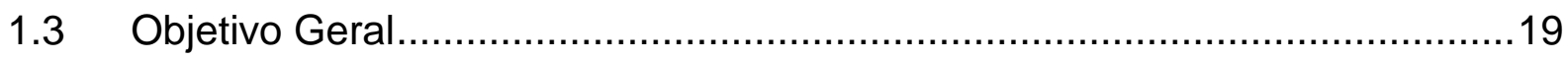

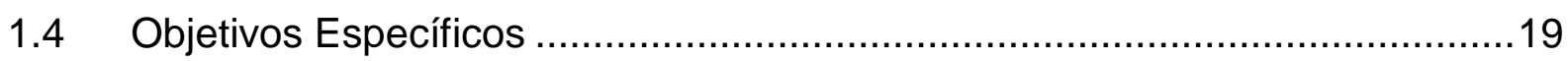

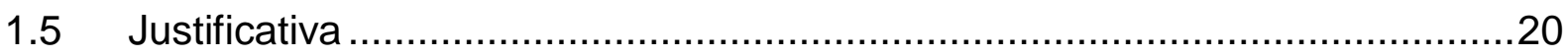

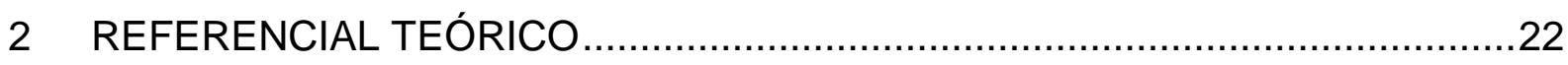

2.1 O Processo de Internacionalização ........................................................22

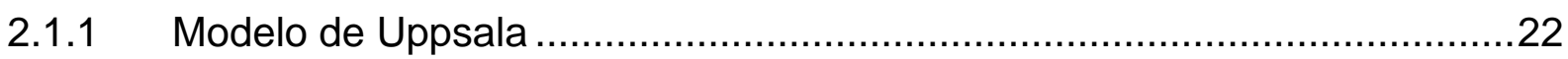

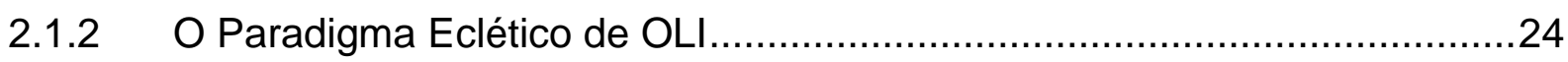

2.2 Internacionalização de Serviços ...........................................................26

2.3 Internacionalização de Serviços Financeiros .............................................27

2.4 Internacionalização de Serviços de Seguros .............................................29

2.5 Dimensões Estratégicas da Internacionalização .........................................30

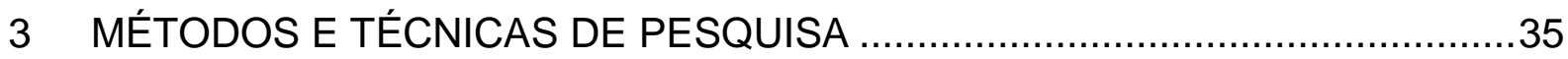

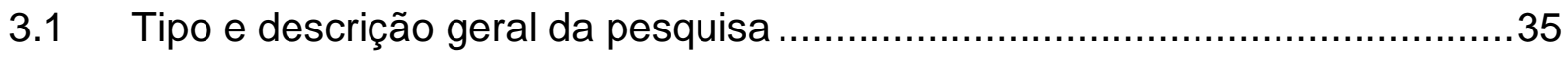

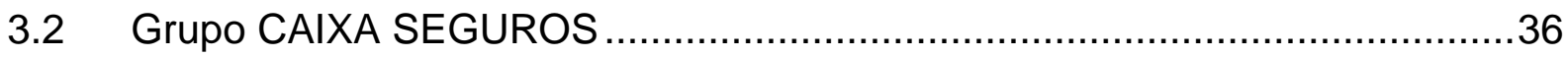

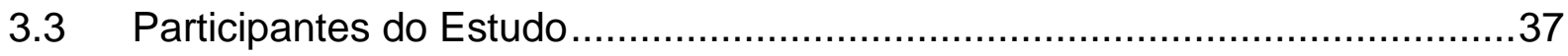

3.4 Instrumentos de pesquisa e fonte de evidência...........................................37 
3.5 Procedimentos de coleta e análise de dados .38

4 RESULTADOS E DISCUSSÃO .39

4.1 Histórico Empresarial da Caixa Seguros 39

4.2 Entendimento das razões da CNP Assurance... 42

4.3 A Estratégias de Internacionalização da CNP Assurance 44

4.4 O modo de Entrada e as Teorias de Internacionalização 45

4.4.1 A entrada da CNP e o Modelo de Uppsala 46

4.4.2 A entrada da CNP e Paradigma Eclético de OLI 46

4.5 A Internacionalização de serviços e o modo de entrada da CNP 47

4.6 O Modo de entrada da CNP e a Internacionalização de Serviços Financeiros e Seguros .48

CONCLUSÕES E RECOMENDAÇÕES 50

REFERÊNCIAS 53 APÊNDICES. 57 Apêndice A - Principais Prêmios e Reconhecimento do grupo CAIXA SEGUROS..57 Apêndice B - Roteiro de entrevista semi-estruturado .58

ANEXOS .60

Anexo A - Organograma do Grupo CAIXA SEGUROS 60

Anexo B - Resultados Financeiros do Grupo CAIXA SEGUROS 60 


\section{INTRODUÇÃO}

O propósito deste estudo é abordar os aspectos envolvidos no processo de internacionalização de empresas de serviços financeiros, mais especificamente de serviços de seguros, com a finalidade de entender o processo de internacionalização usado por uma companhia do setor de seguros ao entrar no mercado brasileiro e identificar os pontos em comum existentes com os demais estudos de processos de internacionalização do setor de serviços.

Atualmente, países em desenvolvimento têm sido alvo de investimentos de muitas empresas estrangeiras. Em análise de mercado e potencial de crescimento, estes países são considerados altamente rentáveis para se investir a um baixo risco (LITAN, MASSON, POMERLEANO, 2001). Entre estes países, podem-se citar os BRICs, de que fazem parte Brasil, Rússia, Índia e China. Países que têm apresentado altas taxas de desenvolvimento, em consequência, altos rendimentos para as empresas que investem e neles se instalam.

Um dos maiores desenvolvimentos financeiros em países emergentes nas últimas décadas foram os enormes crescimentos em Investimento Direto Externo (IED): de US\$36 bilhões anuais em 1991 para US\$ 583 bilhões anuais em 2009, de acordo com o Global Development Finance (WORLD BANK, 2009).

A presença de firmas estrangeiras traz para os países em desenvolvimento enormes vantagens, tais como: aumento de investimentos, maior uso de tecnologias inovadoras, melhores práticas gerenciais, como a gerência de riscos e, por ajudar a diversificar instituições locais, traz mais estabilidade ao país (LITAN, MASSON, POMERLEANO, 2001). Neste sentido, as instituições financeiras estrangeiras têm sido bem-vindas nos países em desenvolvimento para aumentar a competitividade e eficiência dos bancos domésticos, resultando em menores custos de operação.

Não apenas a entrada de bancos é importante para o país, mas também a entrada de empresas seguradoras é importante para distribuir o custo do risco, promover a estabilidade econômica para as famílias e firmas, e incentivar a poupança. Os principais países em desenvolvimento para as seguradoras escolherem como os melhores mercados para atuar são os países que possuem altas taxas de poupança 
e um fraco ou inexistente sistema de previdência pública (LITAN; MASSON; POMERLEANO, 2001).

De acordo com Litan, Masson e Pomerleano (2001), algumas das razões para instituições financeiras expandirem seus negócios para países em desenvolvimento são para aumentar seus lucros e seguir clientes corporativos que passaram a operar nestes mercados.

\subsection{Contextualização}

Ao documentar as tendências de internacionalização global, Nicoló, Bartholomew, Zaman e Zephirin (2004), notaram aumentos nas fusões e aquisições alémfronteiras durante o período de 1985-1995, com cerca de 15\% das transações envolvendo aquisições de instituições financeiras por bancos de países desenvolvidos com participações parciais em alguns mercados emergentes. Relataram que, para o período 1986-1998 houve um aumento substancial nas fusões e aquisições internacionais e nas intranacionais dos bancos europeus, enquanto que fusões e aquisições intranacionais, embora com algum aumento, tornaram-se menor em relação às transações domésticas dos Estados Unidos.

BIS (2001) discutiu a internacionalização envolvendo os mercados emergentes documentando o aumento de entrada de bancos estrangeiros em muitas nações em desenvolvimento. O estudo do BIS (2001) observou as crises bancárias, a desregulamentação e a redução de restrições à entrada de estrangeiros como catalisadores importantes do aumento da penetração dos bancos estrangeiros em alguns países emergentes. A entrada de estrangeiros mostrou ter sido intensa no Leste da Europa e em alguns países latino-americanos, enquanto que era relativamente deixada para trás a entrada na Ásia.

Segundo Nicoló, et al (2004), os incentivos para as empresas financeiras expandirem internacionalmente dependem das oportunidades de lucro percebidas em relação aos disponíveis no mercado doméstico, bem como o ambiente regulatório do país de entrada. Focarelli e Pozzolo (2001) documentaram que os 
bancos com expansões no exterior são grandes, lucrativos e com as sedes nos países desenvolvidos.

O mercado de seguros varia bastante em tamanho e estrutura entre países. O tamanho do mercado de seguros de um determinado país depende muito do tamanho da economia deste e inumeráveis influências ambientais que também modificam a estrutura. A mais comum medição do tamanho do mercado de seguros é por meio do Gross Direct Premium. Globalmente o Gross Direct Premium totalizou mais que US\$2.324 trilhões em 1999, após obter uma média anual de crescimento real em torno de $4 \%$ nos 10 anos anteriores. Países em desenvolvimento no sul e leste da Ásia, Europa Oriental e America Latina passaram, particularmente, por uma forte expansão de mercado nos anos de 1990, porém a crise econômica asiática retardou o crescimento desta região no final da década. O crescimento do prêmio de seguros nos mercados emergentes foi aproximadamente o dobro das economias avançadas durante todas as décadas de 1980 e 1990, no entanto, as economias avançadas continuam a dominar o valor dos prêmios por todo o mundo (LITAN; MASSON; POMERLEANO, 2001).

Segundo Litan, Masson e Pomerleano, (2001), o mercado de seguros possui um ambiente diferente para cada país. A interação de forças da demanda e oferta determina a estrutura do mercado. Preço e inumeráveis fatores econômicos, sociais e culturais influenciam a demanda por seguros. No nível nacional, a demanda de seguros é fortemente relacionada com os rendimentos nacionais. Quanto maiores os rendimentos nacionais, maiores são as compras de seguros de vida e bens em relação aos países de menores rendimentos. Economias em desenvolvimento aumentam os rendimentos e os ativos, juntamente com a demanda por protegê-los e o dinheiro pago pelos prêmios.

As alterações nos mercados de serviços financeiros, os avanços das tecnologias de comunicação e computação, e os aumentos de investimentos para a sofisticação dos serviços aos consumidores têm afetado o mercado por todo o mundo. Todas essas rápidas mudanças pelas quais o mercado global tem passado alteram os riscos e desafios do setor de seguros, o qual tem mudado drasticamente nos últimos 20 anos. Mudanças estas que variam globalmente e localmente de acordo com os desafios pelos quais as firmas e o mundo financeiro passam. Devido a todas as diferenças que há no mercado de seguros, é importante evitar uma visão simplista 
deste mercado. Muitos com pensamento global do mercado e suas influências homogêneas esquecem-se de que no mercado de seguros existem diferenças específicas da localidade, o qual alterará a forma de atuação de uma empresa de seguros (CUMMINS; VENARD, 2008).

Dentre as similaridades do mercado de seguros mundial, as mais importantes que podemos listar são a desregulamentação, intensificação de competição, um rápido crescimento em vendas de seguros, o surgimento de novos canais de distribuição, desenvolvimento tecnológico, reformas na saúde e previdência privada, risco global, diversificação de riscos e a convergência de seguros, serviços bancários e outros serviços financeiros. Já o mercado de seguros local apresenta algumas especificidades que devem ser observadas, como a diversidade do desenvolvimento econômico e do mercado financeiro, variações do sistema político, diferenças na perspectiva de vida da população, diferenças das regulamentações, variações no comércio eletrônico, diferença nos portfólios e diferenças estratégicas das companhias de seguros (CUMMINS; VENARD, 2008).

Cummins e Vernard (2008) apontam a privatização do mercado internacional de seguros como um grande negócio. Muitos países que anteriormente contavam com empresas de seguros governamentais agora têm empresas privadas de seguros como agentes econômicos dominantes. Muitos países testemunharam grandes ondas de privatização. O número de companhias de seguros estatais é cada vez menor, e alguns países têm, quase totalmente, eliminada a gestão governamental das companhias de seguros. Atualmente, essa tendência ocorre não só para alguns países desenvolvidos, como França, mas também para os países do bloco Oriental e as economias emergentes.

Um exemplo de privatizações do mercado internacional de seguros é a Índia, por um longo tempo foi um mercado de seguros protegido onde o seguro de vida foi nacionalizado em 1956 e de seguros de bens em 1972, autorizando o desenvolvimento do setor privado de seguros apenas em 2000. Desde 1988, a China também tem visto o desmantelamento progressivo do monopólio governamental de seguros. O Brasil teve um programa de "nacionalização", em 1937, no qual todas as companhias de seguros tinham de ser brasileiras, nenhuma empresa poderia ser totalmente controlada por sócios estrangeiros e a participação majoritária nacional tornou-se a regra. Em 1996, o mercado brasileiro foi aberto 
novamente aos investidores internacionais, impactando imediatamente, com um aumento de companhias estrangeiras no mercado de seguros em 6\% em 1996 para o valor de 30\% em 2008 (CUMMINS; VENARD, 2008).

Após uma análise do volume anual dos prêmios recebidos em 147 países no período de 1999 a 2006, Cummins e Vernard (2008) mostraram o potencial do mercado de seguros comparado com o volume dos prêmios. Os resultados desta pesquisa apontaram que o mercado de seguros está, de fato, concentrado em cinco países: Estados Unidos, Brasil, Japão, África do Sul e Austrália.

Já Millet (2010) aponta o Brasil como o maior mercado de seguros da América Latina por possuir a maior população deste continente, é a 10ª maior economia do mundo pelo GDP e possui uma baixa taxa de penetração do mercado de seguros. $O$ que indica que, apesar do impressionante tamanho potencial do mercado de seguros no Brasil, ele ainda tem como crescer muito, sendo estimado o terceiro maior mercado, perdendo apenas para a China e Índia nos mercados emergentes.

Porém, o mercado brasileiro apenas tornou-se realmente atraente para os bancos e seguradoras internacionais a partir do momento em que ocorreram algumas reformas regulamentares. Inicialmente, as propostas de reformas regulamentares para o setor foram em 1992 pela FENASEG - Federação Nacional das Empresas de Seguros Privados Previdência e de Capitalização, mediante a Carta de Brasília. Esta carta foi a primeira manifestação consensual das empresas de seguros com uma proposta de mudanças. A carta enfatizava a necessidade da ampliação da imagem pública do seguro, a desregulamentação do setor, e algumas propostas de modernização da atividade seguradora. A partir das propostas da Carta de Brasília, em 1996, houve a liberação da entrada de empresas estrangeiras no mercado e a Advocacia Geral da União considerou inconstitucional a Resolução CNSP no 14/86, que impedia que o capital estrangeiro participasse com mais de $50 \%$ do capital ou um terço das ações de seguradora brasileira. Imediatamente mais de 20 empresas estrangeiras entraram no Brasil a partir de Junho de 1996 (HISTÓRIA, 2010).

A desregulamentação e a abertura do mercado de seguros ao exterior trouxeram ao Brasil um número expressivo de seguradoras estrangeiras, atraídas pelo tamanho do mercado. Este mercado estava representando cerca de 50\% da América Latina, por indicadores demográficos, como a alta parcela da população abaixo de 40 anos e pelo potencial de crescimento, expresso em quocientes prêmio/PIB e prêmios per 
capita relativamente baixos. A forma majoritária pela qual essas empresas entraram no país foi via joint ventures e aquisições de seguradoras nacionais, de modo a evitar o problema do fraco conhecimento das marcas por parte dos consumidores nacionais (FARIA, 2005).

Essa abertura do mercado brasileiro às seguradoras estrangeiras mantém estrita sintonia com a tendência de globalização dos mercados, que nos últimos anos vem ocorrendo em escala planetária. Trata-se de um processo que, abrangendo o mundo inteiro, induz à quebra das barreiras e dos isolamentos geográficos, e ao surgimento de um novo quadro de relações produtivas, em que o capital a cada dia torna-se menos político e mais financeiro que nunca. E o Brasil, pelo porte de sua economia, desponta com irresistível apelo aos capitais globalizados, e tem sabido aproveitar essa vantagem conjuntural: somente em 1998 o país recebeu mais de U\$28,7 bilhões em investimentos externos diretos (HISTÓRIA, 2010).

Assim, de uma participação pouco significativa na década de 80 , as firmas estrangeiras detiveram, em 2002, cerca de $35 \%$ da receita de prêmios e constituíram $30 \%$ do total de seguradoras instaladas no Brasil. O número de seguradoras operando no Brasil aumentou de 115, em 1990, para 140, em 2002. A entrada de tais empresas e o consequente aumento da concorrência representou e continua representando um desafio para as seguradoras nacionais que, no geral, têm uma experiência menos intensa que as estrangeiras em programas de redução de custos, melhora na avaliação de riscos e incremento de canais de distribuição. (FARIA, 2005).

Como exemplo de empresas que entraram no Brasil a partir de 1996, podemos citar a Swiss Life, a segunda maior seguradora de vida na Europa, que desde 1996 tem a Icatu Seguros, uma empresa brasileira, como representante exclusiva. Em 2002, a SulAmérica, de origem brasileira, celebrou uma parceria com o ING, uma Companhia de origem holandesa, com atuação mundial no ramo de serviços bancários, de seguros e administração de recursos. Em 30 de setembro de 2009 detinha, direta e indiretamente, $36 \%$ do capital social total da SulAmérica (PERFIL, 2011). 


\subsection{Formulação do problema}

Diversas empresas encontram diferentes formas de internacionalizar suas operações e serviços, e ainda apresentam diferenciações do modo de entrada de país para país. Os modelos de internacionalização argumentam que as habilidades que as firmas possuem de controlar a produção interna e os processos de distribuição, assim como a economia externa, fatores políticos e culturais, influenciam nos métodos encontrados de entrada em mercados estrangeiros (JOHANSON, VAHLNE, 1977; DUNNING, 1980; BLOMSTERMO, SHARMA, 2006; PEINADO, BARBER, 2006; JOHANSON, VAHLNE, 2006; DUNNING, LUNDAN, 2008). De acordo com Outreville (2008), por razões diferentes, economias em transição ou em desenvolvimento tendem a atrair seguradoras estrangeiras por serem mercados que dão sinais positivos de crescimentos futuros. Para contribuir a entender como se dá o processo de internacionalização no setor de seguros, formulou-se a seguinte pergunta de pesquisa: Como e porque a empresa francesa CNP Assurance entrou no Brasil atuando no mercado financeiro e de seguros?

\subsection{Objetivo Geral}

O objetivo geral do trabalho é descrever o processo e identificar os fatores de entrada da CNP Assurances no Brasil como acionista da CAIXA SEGUROS.

\subsection{Objetivos Específicos}

Para que se possa atingir o objetivo geral, propõem se os seguintes objetivos específicos:

- Descrever o processo de entrada da Empresa no Brasil; 
- Identificar as incertezas e desafios encontrados na entrada e adaptação ao mercado brasileiro;

- Identificar e caracterizar o modelo de crescimento da empresa dentro do mercado brasileiro.

\subsection{Justificativa}

Em 2009, no Brasil, a participação de serviços no PIB foi de $68,5 \%$ e é responsável por $70 \%$ dos empregos formais (BRASIL). Os serviços de intermediação financeira, seguros e previdência complementar e serviços relacionados, representam $12,6 \%$ da participação de serviços no PIB. Os serviços têm se tornado a grande força da economia global (JAVALGl; GRIFFITH; WHITE, 2003). Apesar de o setor de serviços ser mais importante que o setor industrial na economia brasileira e de outros países em geral, há poucas pesquisas sobre o crescimento e a internacionalização de empresas de serviços (CONTRACTOR; KUNDU; HSU, 2003; JAVALGI; GRIFFITH; WHITE, 2003). Serviços são fundamentalmente diferentes da indústria, como será detalhado no capítulo de Fundamentação Teórica. Entre as características que diferenciam serviços estão a sua relativa intangibilidade, desgaste, simultaneidade de produção e consumo, e customização. (BODDEWYN; HALBRICH; PERRY, 1986).

Segundo Focarelli e Pozzolo (2008) muitos dos estudos sobre internacionalização do setor de serviços financeiros focam principalmente nos serviços bancários, enquanto poucos têm analisado os determinantes e processos de expansão alémfronteiras das companhias de seguros. Neste sentido, pode-se dizer que este trabalho prioriza um contexto de pesquisa que é pouco tradicional na literatura, por duas razões principais: enfoca firmas oriundas de países desenvolvidos operando em países emergentes (REZENDE; VESIANI, 2010) e um estudo do processo de internacionalização de companhias de seguros (HELLMAN, 1994; FOCARELLI; POZZOLO, 2008).

Analisar a entrada de uma instituição de seguros estrangeira no Brasil poderia focalizar uma variedade de diferentes aspectos, tais como: as razões da escolha do 
Brasil (CONTRACTOR; KUNDU; HSU, 2002), as barreiras encontradas (CONTRERAS; YI 2003), as similaridades e diferenças culturais (JOHANSON; VAHLNE, 2006), o processo usado para a entrada (FORSGREN, 2002), se o processo e razões de entrada no Brasil foram os mesmos para entrar em outros países (DUNNING; LUNDAN, 1980, 2008; FORSGREN, 2002), quais os principais fatores que ajudaram na consolidação (DUNNING; LUNDAN, 1980, 2008; FORSGREN, 2002), entre outros. Portanto, diante da diversidade de assuntos possíveis a serem abordados escolheu-se - por considerá-los mais importantes devido ao presente estado de conhecimento sobre processo de internacionalização de empresas de serviços de seguros - abordar apenas como foi o processo de entrada, as incertezas e desafios para atuar no mercado brasileiro e caracterizar o modelo de crescimento.

Assim, o trabalho poderá contribuir com outros estudos referentes à internacionalização de serviços, ao exemplo de Contractor, Kundu e Hsu (2003), para avançar os estudos de internacionalização de serviços financeiros, especificamente os de seguros, ajudando a entender melhor o processo de entrada em um mercado emergente - no caso, o brasileiro - desse tipo de serviços. 


\section{REFERENCIAL TEÓRICO}

O desenvolvimento desta seção foi feito a partir dos principais conceitos sobre os processos de internacionalização, em aspectos voltados às estratégias das organizações. Sendo assim, conceituam-se os principais modelos de internacionalização para, em seguida, focar nos processos de internacionalização para o setor de serviços, em geral, e o subsetor de serviços financeiros.

\subsection{O Processo de Internacionalização}

Para Javalgi, Griffith e White (2003), o processo de internacionalização é considerado um processo mediante o qual uma empresa move suas operações domésticas para os mercados internacionais. Os conceitos de Internacionalização e as formas de internacionalização têm recebido muitas atenções no que diz respeito às estratégias da organização (JOHANSON; VAHLNE, 1977; DUNNING, 1980; FORSGREN, 2002; PAIVA; HEXSEL, 2004; JOHANSON; VAHLNE, 2006; DUNNING; LUNDAN, 2008; RESENDE; VERSIANI, 2009).

Estes autores citados desenvolvem os dois principais conceitos de processos de internacionalização para os setores de serviços e manufatura como estratégias da organização. Dessa forma, os próximos tópicos visam a desenvolver uma breve explicação destes principais processos.

\subsubsection{Modelo de Uppsala}

A partir da década de 70, muitos trabalhos da Universidade de Uppsala foram publicados e estes relatavam a forma como as empresas suecas internalizavam os negócios. Trabalhos que levantaram pontos importantes caracterizaram o fenômeno de internacionalização e se tornaram os fundamentos da Escola Nórdica de Negócios Internacionais. O maior impacto desta linha de pensamento foi contribuir 
para que os estudos de Negócios Internacionais deixassem de focar puramente no fenômeno econômico e analisassem sob uma perspectiva da Teoria do Comportamento Organizacional (HILAL; HEMAIS, 2003).

Johanson e Vahlne $(1977,2006)$ advogam que o processo de internacionalização é o resultado de um foco de desenvolvimento individual da empresa e, principalmente, na gradual aquisição, integração e o uso do conhecimento sobre o mercado externo e as operações, e consequentemente um sucessivo aumento do comprometimento para o mercado externo.

Esta busca pelo conhecimento para aumentar gradualmente a capacidade de análise do mercado externo busca diminuir as incertezas e a distância psíquica que, de acordo com Johanson e Vahlne (1977), é a diferença entre o país de origem da empresa e o país estrangeiro em termos de desenvolvimento, nível e conteúdo educacional, idioma, cultura, sistema político, entre outros. Quanto maior a diferença, maior a incerteza.

Ainda, para Johanson e Vahlne (1977) o conhecimento é importante porque é a base para as decisões de comprometimento da empresa. Contribuindo assim, para o conhecimento de oportunidades e problemas como a base para o início de decisões. Em seguida, a avaliação de alternativas é baseada em alguns conhecimentos sobre o ambiente do mercado e performance de várias atividades. Em geral, o conhecimento contribui para relacionar a demanda presente com a futura, canais de distribuição, condições de pagamento e transferências de dinheiro, e ainda, outros aspectos que variam de país para país e de tempos em tempos.

A partir das ideias de Johanson e Vahlne (1977), Forsgren (2002) apontam-se os quatro conceitos principais do Modelo de Uppsala: conhecimento de mercado, confiança no mercado, confiança de decisões e atividades em andamento. $O$ conhecimento e a confiança de mercado afeta, até certo ponto, a confiança de decisões e como as atividades são desenvolvidas nos períodos subsequentes e, como consequência, influenciará o conhecimento de mercado e a confiança nos estágios seguintes.

Como base nos quatro conceitos principais de Johanson e Vahlen (1977), Forsgren (2002) e fazendo suposições de incrementalismo, sugere-se o Modelo prognóstico como padrão básico de internacionalização de firmas, nas seguintes etapas: 1) 
começar e continuar os investimentos apenas em um ou poucos países vizinhos, preferivelmente, a investir em muitos países simultaneamente; 2) Os investimentos em um país específico são direcionados cuidadosamente, sequencialmente e concomitantemente com o aprendizado das pessoas da firma sobre as operações naquele mercado; 3) As firmas entram em novos mercados com sucessivos aumentos de distância física e os investimentos de mercado aumentam de acordo com o estabelecimento da cadeia.

\subsubsection{O Paradigma Eclético de OLI}

De acordo com Dunning (1980), a propensão de um empreendimento entrar em uma produção internacional financiada pelo investimento direto externo baseia-se em três determinantes: 1) que este empreendimento possui ou pode adquirir meios mais favoráveis, ativos que os competidores não possuem; 2) que é de interesse da firma vender ou arrendar estes ativos para outra firma, ou ainda internalizar estes ativos; 3) quanto maior forem os benefícios de internalização de produtos de mercado para a exportação, maior será a probabilidade de as empresas preferirem realizar a produção estrangeira, preferivelmente do que a licença do direito, como por exemplo, um serviço técnico ou uma rede de franquias para uma empresa estrangeira.

Nesta base, Dunning (1980) desenvolve o Paradigma Eclético, também conhecido como o Modelo OLI. Este modelo aponta como importante não apenas a estrutura organizacional, mas também:

- ownership advantages (vantagens de propriedade): marca, técnica de produção, conhecimentos empreendedores, retorno de escala.

- locational advantages (vantagens de Localização): disponibilidade de matérias-primas, baixos salários, juros especiais.

- internalization advantages (vantagens de internalização): vantagens através de arranjo de associações de produção como as licenças de produção ou joint venture. 
De acordo com Dunning $(1980,2008)$, uma precondição para a internacionalização de atividades de uma companhia é a disponibilidade de net ownership advantages (vantagens que uma companhia tem no exterior ou mercados desconhecidos), podendo estas vantagens ser ou não material.

Para Dunning (2006), enquanto a análise do custo de transação pode determinar que tipo de mercado poderá ser melhor para uma empresa internalizar, qualquer transação pode, potencialmente, ser internalizada por uma ou mais partes, pois quem internaliza algo requer uma explicação que se baseia em específicas capacidades e infraestrutura institucional da firma.

Assim, de acordo com Dunning (1980), os determinantes para a internacionalização da produção dos serviços de seguros seriam:

\begin{tabular}{|l|l|l|l|l|}
\hline $\begin{array}{l}\text { Tipos de } \\
\text { Produção } \\
\text { Interacional }\end{array}$ & $\begin{array}{l}\text { Posse de } \\
\text { Vantagens }\end{array}$ & $\begin{array}{l}\text { Vantagens de } \\
\text { Localização }\end{array}$ & $\begin{array}{l}\text { Vantagens de } \\
\text { Internalização }\end{array}$ & $\begin{array}{l}\text { Tipos de } \\
\text { atividades } \\
\text { favoráveis }\end{array}$ \\
\hline $\begin{array}{l}\text { Serviços } \\
\text { Auxiliares }\end{array}$ & $\begin{array}{l}\text { Acesso ao } \\
\text { mercado }\end{array}$ & Mercado & $\begin{array}{l}\text { Desejo de } \\
\text { exploração de } \\
\text { tecnologia, altas } \\
\text { transações, custo } \\
\text { de informação, } \\
\text { diminuição de } \\
\text { incertezas e } \\
\text { proteger o nome }\end{array}$ & $\begin{array}{l}\text { serviços } \\
\text { bancários e } \\
\text { da companhias. }\end{array}$ \\
\hline
\end{tabular}

Quadro 1: Os determinantes da produção internacional em serviços auxiliares

Fonte: Adaptado de Dunning (1980)

Dessa forma, a Teoria ou Paradigma Eclético de Dunning busca explicar como as firmas do setor de serviços e manufatura iniciam no processo de Internacionalização. 


\subsection{Internacionalização de Serviços}

Para Boddewyn, Halbrich e Perry (1986), os serviços possuem características específicas que os diferenciam dos bens manufaturados. E é exatamente devido a estas diferenças que haverá as divergências no modo de internacionalizar as operações. De acordo com os autores, os serviços possuem algumas peculiaridades como: intangibilidade por natureza, produção e consumo simultâneos e o envolvimento direto do cliente, pois é ele quem solicita os serviços.

Johanson e Vahlne (1990) argumentam que as teorias de processos de internacionalização não são diretamente aplicáveis ao setor de serviços, e que as diferenças entre o setor de manufatura e o de serviços necessitam de um foco no contexto para entender o processo de internacionalização do setor de serviços. Contudo Johanson e Vahlne (2006) desenvolvem seus estudos de entendimento do processo de internacionalização de serviços a partir dos principais modelos de internacionalização aplicados, inicialmente, ao setor de manufatura. (CONTRACTOR; KUNDU; HSU, 2002; BLOMSTERMO; SHARMA, 2006; JOHANSON; VAHLNE, 2006; PEINADO; BARBER, 2006).

Focalizando especificamente a internacionalização de serviços, Blomstermo, Sharma e Sallis (2006) sugerem que as empresas de serviços podem entrar em mercados estrangeiros por meio de uma variedade de modos de entrada, por exemplo, exportações, licenças, joint ventures, ou estabelecendo subsidiárias, além das fronteiras. O modo de entrada no mercado estrangeiro é crucial e relacionado com o controle considerado necessário. O controle é importante, uma vez que ajuda a garantir o alcance dos objetivos principais da organização. Assim como o controle é um significante fator que determinará riscos e retornos, a quantidade de conflito relacional entre compradores e vendedores, e por último, o desempenho do investimento no exterior. O controle em um modo de entrada no mercado estrangeiro permite que as companhias de serviços entreguem pontualmente e com uma qualidade garantida para os clientes internacionais, protegendo assim, a reputação da empresa.

Para melhor entendermos o processo de internacionalização do setor de serviços, é importante estabelecermos uma separação entre os tipos de serviços, em que 
utilizaremos uma divisão que leva em conta principalmente os ativos intangíveis e com um pouco menos de importância o custo do capital fixo. Desta forma, o setor de serviços pode ser separado em dois subgrupos: 1) Setor de serviços baseado em conhecimento; 2) Setor de serviços de capital intensivo (CONTRACTOR; KUNDU; HSU, 2002; BLOMSTERMO; SHARMA; SALLIS, 2006; PEINADO; BARBER, 2006).

Para Contrator, Kundu e Hsu (2002) e Peinado e Barber (2006) o subgrupo baseado em conhecimento constitui-se das empresas em que o conhecimento tem a maior importância, o capital humano domina o capital financeiro e os recursos físicos. Incluem neste grupo os serviços de marketing, advertising, seguros e serviços financeiros diversos. O subgrupo de capital intensivo é constituído pelas empresas que necessitam de um alto investimento financeiro para sua expansão e instalação, representando assim uma barreira de entrada e saída de países estrangeiros. Incluem os serviços aéreos, telecomunicação, construção, hotel, restaurantes e cadeias de fast food, entregas e transporte rodoviário.

Para Peinado e Barber (2006) há diferenças do modo de entrada de acordo com o subgrupo a que uma empresa pertence. O subgrupo de serviços intensivos em conhecimento prefere entrar em mercados estrangeiros usando maior controle das operações do que o subgrupo de serviços intensivos em capital - como, por exemplo, geração de energia elétrica - quando operam em países de maior risco e incerteza cultural. Para o primeiro subgrupo, o baixo investimento necessário para iniciar as operações internacionais e a dificuldade de transferência de conhecimento tácito para outras pessoas é condicionado mais pelas oportunidades competitivas do país estrangeiro do que pela estabilidade econômica e política de países com culturas similares ao país de origem.

\subsection{Internacionalização de Serviços Financeiros}

De acordo com Contreras e Yi (2003) características muito particulares de serviços financeiros fazem a sua internacionalização dependente de uma série de diferentes e complementares reformas regulamentares. Estas formam a liberalização do comércio, reforma das regulamentações financeiras nacionais e a eliminação de restrições ao fluxo além-fronteiras de capitais. Diferentemente de outros negócios de 
serviços que podem ser efetuados mediante uma ou combinações de até quatro modos de fornecimento dos serviços financeiros. Os modos são o fornecimento além-fronteiras, consumo no exterior, presença comercial e movimento de pessoas originárias do país estrangeiro. São geralmente substitutos, cuja exigência desregulatória (comércio, regulamentos internos ou fluxos de capital) difere substancialmente das barreiras regulatórias para os serviços financeiros.

Assim, os decisores políticos buscam encontrar uma combinação e sequência de reformas que, ao promover a internacionalização dos serviços financeiros, não afete negativamente a estabilidade do sistema financeiro. De fato, uma das mais importantes razões para a falta de abertura do comércio e investimentos alémfronteira nos serviços financeiros, em nível multilateral, em particular pelos países em desenvolvimento, refere-se ao fato de ela tem sido associada com a instabilidade do mercado financeiro e de fluxo de capitais voláteis (CONTRERAS; YI, 2003).

De acordo com uma pesquisa de Nicoló, et al (2004), um motivador principal para a fusão e aquisição como processo de internacionalização das instituições financeiras é a contribuição para a redução de custos e aumento de retornos. Porém, há também outros fatores encorajadores para a busca de fusões e aquisições para estes serviços, tais como, o maior desenvolvimento de tecnologias da informação, desregulamentação financeira, globalização e aumento de performance financeira. Há ainda outros fatores que contribuem para a ocorrência de fusões e aquisições em países em desenvolvimento: crises bancárias e privatização de bancos governamentais, os quais optam por investimentos externos e consolidação com empresas estrangeiras para aumentar a eficiência.

Para Focarelli e Pozzolo (2008), as fusões e aquisições internacionais são os meios mais importantes e usados pelas firmas financeiras para expandir suas atividades além-fronteiras, apesar desta prática de fusões e aquisições ainda ser menor do que no setor de manufatura. Utiliza-se deste modo de entrada para diminuir os riscos e as barreiras presentes nos países estrangeiros que dificultarem a entrada destes serviços. Observam, ainda, que os fatores geográficos e proximidade cultural são mais importantes que os custos de vantagens na formação da expansão alémfronteiras.

Como principais razões para a expansão dos serviços financeiros, sugerem que seria decorrente da internacionalização do setor de manufatura - portanto, 
internacionalizando para seguir o cliente - e da oportunidade de lucros apresentada pelos serviços financeiros no mercado externo, sendo maior o potencial de lucro nos países em desenvolvimento (LITAN, MASSON, POMERLEANO, 2001).

Em adição à possibilidade de lucros, Focarelli e Pozzolo (2008) observaram que há maior probabilidade de os bancos expandirem suas operações para países que possuem o PIB per capita baixo, nível de educação alto, mercado financeiro e de crédito alto e a taxa de inflação baixa, métricas associadas com maior expectativa de crescimento econômico.

\subsection{Internacionalização de Serviços de Seguros}

A Internacionalização dos Serviços de Seguros para países em desenvolvimento, principalmente, é determinada pela alta possibilidade de crescimento e de lucros (LITAN, MASSON, POMERLEANO, 2001). Estudos de correlação de Focarelli e Pozzolo (2008) mostram que há maior probabilidade de empresas de seguros são mais prováveis de expandir suas operações para países que são mais próximos geograficamente, têm mercado de grandes proporções, apresentam maior eficiência do ambiente jurídico, possuem sistemas de telecomunicações mais desenvolvidos, e um maior nível de educação.

Segundo Focarelli e Pozzolo (2008), as companhias de seguros estão mais dispostas a internacionalizarem suas operações mediante fusões e aquisições se estas vierem de países que possuem PIB per capita maior que o país a ser entrado e ainda que possuam maior penetração de empresas de seguros.

De acordo com Outreville (2008), a oportunidade do mercado estrangeiro tornou-se possível a partir da desregulamentação e globalização. Muitas empresas seguradoras têm aumentado os investimentos externos e adquirido outras seguradoras, por acreditarem que somente as grandes empresas seguradoras terão as vantagens de custo necessárias para permanecerem competitivas em mercados em desenvolvimento. Por diversos motivos, conforme citado na introdução, economias em transição e em desenvolvimento tendem a atrair empresas de seguros. 
Outreville (2008) examina a presença das 30 maiores companhias seguradoras multinacionais do mundo, à luz do Paradigma Eclético de OLI, verificando o seguinte sobre suas razões de expansão:

a) ownership advantages (vantagens de propriedade): seguros dependem de informações e conhecimentos técnicos, e a habilidade de dispersar o risco confere uma relativa vantagem para algumas companhias.

b) locational advantages (vantagens de Localização): distância geográfica e cultural e o impacto direto e indireto no custo da informação, o nível de infraestrutura do país (educação e leis), mudança nas oportunidades regulatórias do mercado (desregulamentação) para negócios de serviços de seguros e por fim, o tamanho do mercado e o rendimento deste.

c) internalization advantages (vantagens de internalização): exploração de recursos para participar de atividades globais ou a necessidade para dividir o risco.

Os resultados dos estudos de correlação com as 30 maiores seguradoras multinacionais do mundo, desenvolvidos por Outreville (2008), mostram que as vantagens de localização como tamanho do mercado, educação, barreiras, competitividade e distância cultural realmente influenciam as decisões de internacionalização das companhias. Observou-se, também, que considerações relacionadas à governança corporativa, medidas pela corrupção, e efetividade do governo tem um grande impacto na escolha de entrada de companhias seguradoras no país.

As teorias de internacionalização, em geral, apontam as fusões e aquisições como o mais usado e o mais seguro processo para a entrada de outros países, conforme citado anteriormente.

\subsection{Dimensões Estratégicas da Internacionalização}

Empresas que atuam em ambientes domésticos estáveis possuem a atenção voltada aos fatores competitivos e tecnológicos que determinam o sucesso no 
mercado. Porém, quando passam a atuar no exterior, os gestores esperam encontrar novos concorrentes e uma dinâmica de competição diferente. E, além das variáveis de competição, o sucesso em outros mercados pode depender de outros fatores que permanecem em um plano secundário, enquanto que a empresa restringe a atenção apenas aos mercados internos. Contudo, uma combinação da diferença destes fatores secundários pode ser tão importante no novo mercado, quanto os fatores de competição (ANSOFF; MCDONNELL, 1993).

Ansoff e McDonnell (1993) apontam estes fatores secundários como fatores econômico, cultural e político. No aspecto econômico o meio estrangeiro pode apresentar diferenças do meio doméstico em níveis de desenvolvimento econômico, tamanho do mercado total para os produtos da empresa, grau de saturação do mercado e outros. Em seguida no fator cultural, a AEN - Área Estratégica do Negócio - estrangeira, pode apresentar diferenças nos gostos dos consumidores, hábitos de compras, alocação de orçamentos dos clientes, capacidade dos clientes para usar produtos tecnologicamente sofisticados, etc. Por último, o fator político, o qual a ideologia do Governo do novo país pode ser diferente da ideologia doméstica. Consequentemente, as atitudes em relação à empresa podem ser diferentes, assim como os regulamentos, restrições e incentivos sob os quais a empresa deve operar.

Dessa forma, para a entrada em um país estrangeiro, é necessário adquirir muito mais informações para a tomada de decisões comerciais no ambiente doméstico. Para sucesso no ambiente doméstico, as empresas são forçadas a desenvolver potencialidades de monitoramento quando 0 ambiente doméstico se torna turbulento. Logo, empresas que tenham passado por uma experiência doméstica de turbulência econômica, política ou tecnológica acham-se mais bem preparadas para internacionalização do que as empresas de um ambiente tradicionalmente calmo. Porém a coleta dessas informações em países estrangeiros pode enfrentar alguns problemas, pois muitas das informações não são quantificáveis, ou não perceptíveis por um estrangeiro. Estas informações só podem ser perceptíveis por um cidadão nativo ou um estrangeiro que viveu suficientemente no país para conhecer os fatores de sucesso cruciais e sutis (ANSOFF; MCDONNELL, 1993).

No mesmo sentido da diversificação doméstica, a internacionalização necessita de focar nos objetivos da empresa: quais aspectos do desempenho a empresa deseja melhorar com a internacionalização. Necessitando ficar bem claros, em ambos os 
casos, quais são os objetivos e os critérios estratégicos utilizados na busca e na avaliação de alternativas que direcionarão a empresa para AENs que atendam a estes objetivos. Dentre os objetivos mais almejados pela diversificação ou internacionalização apontados por Ansoff e McDonnell (1993) citam-se:

- Crescimento de volume/tamanho - crescer e evitar a estagnação causada pela saturação das AENs tradicionais. Elevar o crescimento histórico e ainda positivo. E, por fim, aumentar o volume e o tamanho da empresa através do ingresso em AENs com perspectivas de crescimento comparáveis.

- Melhoria de rentabilidade - aumentar as perspectivas de rentabilidade em longo prazo, ingressando em mercados em estágios iniciais de crescimento. Aumentar elou manter a rentabilidade em curto prazo, através de mercados com sinergia ou economias de escala significativas. E por fim, aumentar a rentabilidade, em curto prazo, ingressando em mercados rentáveis.

- Equilíbrio da carteira estratégica da empresa - garantir a rentabilidade e o crescimento continuados da empresa, para preencher lacunas em sua carteira de ciclos de vida de demanda e tecnologia. Garantir a invulnerabilidade futura da empresa a ciclos, pertubações e descontinuidades de origem tecnológicas, ecnonômicas ou sociopolítica. Este objetivo contribui para o posicionamento em mais de uma tecnologia e mais de um sistema sociopolítico, o único peculiar apenas à internacionalização.

Portanto, a partir dos objetivos descritos anteriormente, a diversificação doméstica oferece a vantagem de um ambiente sociopolítico/cultural/econômico familiar, mas apresenta o risco e o custo da entrada em ramos desconhecidos. Já a internacionalização tem como vantagem a extensão de atividades familiares à empresa, e as desvantagens e riscos de ter que aprender sobre ambientes estranhos.

Empresas que optam por um envolvimento progressivo para a internacionalização geralmente o fazem devido ao custo da informação estratégica. O custo da informação estratégica é mais elevado do que o custo da informação sobre o mercado doméstico, e alguns dos conhecimentos vitais sobre ambientes estrangeiros só são adquiridos com a experiência direta. Neste sentido, Ansoff e 
McDonnell (1993) citam as etapas para realizar um envolvimento gradativo planejado:

1. Formulação de uma estratégia mundial de internacionalização: a) comparando os objetivos da empresa com os critérios estratégicos, identificando as regiões geográficas e AEN que satisfaçam os critérios; b) incluindo a especificação de diferenças estratégicas de produto, tecnologia, marketing, produção e distribuição.

2. Busca de AEN que encaixe na estratégica.

3. Análise dos mercados de acordo com a atratividade, viabilidade nos custos de entrada, intensidade da concorrência e perspectivas de cresimento e rentabilidade.

4. Análise de entrada ou saída e que estratégia de competição deve ser adotada.

5. Decisão por algum empreendimento experimental se um mercado externo for muito atraente, mas caro. Podendo haver diferentes possibilidades em seguida: a) retirada rápida porque a $\mathrm{AEN}$ é impossível de tornar rentável; b) retirada após o esgotamento da oportunidade de alta rentabilidade temporária; c) conversão para um empreendimento permanente se há potencial de lucro a curto e longo prazo.

6. Gerência experimental do empreendimento como um aprendizado estratégico, ou seja, focar em entender o empreendimento e se será lucrativo no curto e longo prazo.

7. Decisão de continuar vendendo na AEN enquanto houver potencial de lucro em curto prazo, porém minimizando o comprometimento de recursos.

8. Decisão de fixar permanentemente no mercado, se este apresentar atraente a um custo razoável.

Em resumo, apresentamos as fases do envolvimento gradativo, conforme figura: 

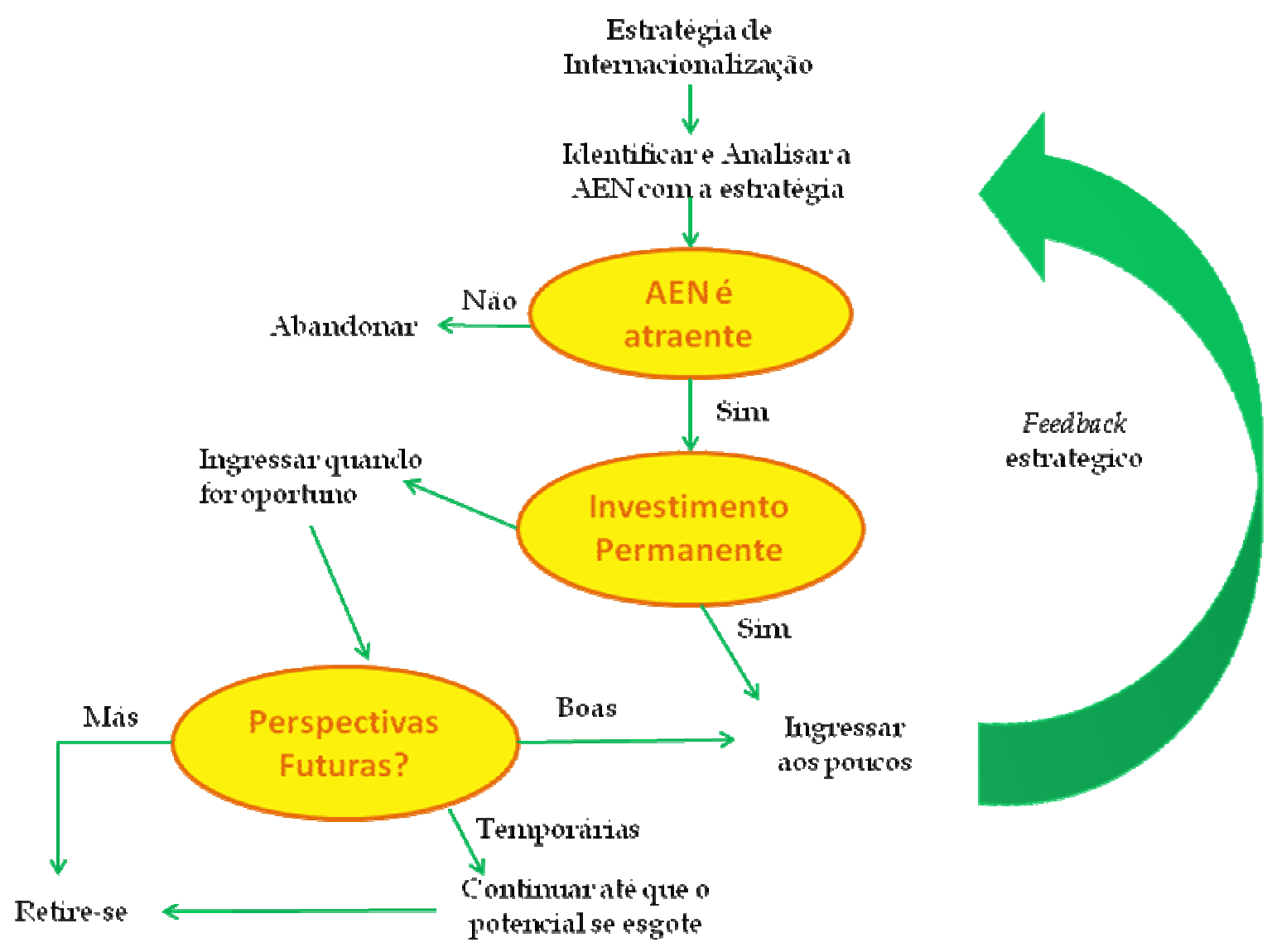

Figura 1: Envolvimento gradativo

Fonte: Ansoff e McDonnell, (1993, pag 277) 


\section{MÉTODOS E TÉCNICAS DE PESQUISA}

Nesta seção será apresentado o método de pesquisa utilizado e os instrumentos de pesquisa para a obtenção dos dados que dão consistência ao estudo. Serão descritos os procedimentos utilizados na coleta e análise dos dados obtidos.

\subsection{Tipo e descrição geral da pesquisa}

O método de pesquisa utilizado foi o estudo de caso, que para Yin (2005) lida de forma adequada com o planejamento, análise, e a exposição de ideias. Possui uma capacidade de lidar com uma ampla variedade de evidências, documentos, artefatos e observações. Como um método de pesquisa, o estudo de caso contribui de forma inigualável para compreender os fenômenos individuais, organizacionais, sociais e políticos, fenômenos com características sociais complexas. E ainda utiliza-se o estudo de caso quando se quer deliberadamente lidar com condições contextuais, acreditando que elas poderiam ser altamente pertinentes ao seu fenômeno de estudo.

A pesquisa realizada caracteriza-se como descritiva quanto aos fins, a qual expõe características de determinado fenômeno ou população. Estabelece relação entre variáveis e definição de sua natureza, e não possui o compromisso de explicar os fenômenos que descreve, embora ajude a apoiar a explicação (VERGARA 2005). Possui o objetivo de refletir sobre a realidade da forma mais fiel possível, exigindo, para que a pesquisa seja válida, uma delimitação de técnicas, métodos de coletas e interpretação de dados precisos (RICHARDSON, 1999)

Quanto aos meios, caracteriza-se como qualitativa com roteiro de entrevista semiestruturado e uma análise documental (VERGARA, 2005). Caracterizada como qualitativa em virtude da ausência de um instrumental estatístico na análise do problema, pois não objetiva enumerar, medir unidades ou categorias homogêneas (RICHARDSON, 1999). Assim, buscou-se obter aspectos mais relevantes de 
determinado problema de acordo com o ponto de vista dos entrevistados, os quais foram os atuais diretores que foram envolvidos nos processos de entrada da CNP Assurances. Conjuntamente, a análise dos documentos garantiu a análise física e suportou o entendimento dos aspectos envolvidos nesta entrada. Os documentos consistiram em alguns dados financeiros para análise do desempenho para ambas as empresas, antes e após a entrada da CNP Assurances no Brasil, estratégias das empresas, e outros que foram disponibilizados pelos diretores da Caixa Seguros e que contribuíram para entender todo o processo.

\subsection{Grupo Caixa Seguros}

Fundada em 22 de maio de 1967, no Rio de Janeiro, a SASSE, atual Caixa Seguros, até o início da década de 90 trabalhava, prioritariamente, em quatro segmentos de seguros: acidentes de trabalho, incêndio, vida e invalidez permanente. Em 1991 ganhou visibilidade ao assumir a administração dos seguros habitacionais da CEF. O ano de 2001 marca a entrada da multinacional francesa CNP Assurances para 0 time de acionistas. A empresa, líder do mercado de seguro de pessoas da França, passa a assumir o controle acionário, com $51,75 \%$ das ações, tendo a CEF mantida sua participação acionária com 48,21\%. Atualmente, a seguradora está entre as dez maiores empresas do setor no Brasil. Registra-se também que é o único grupo segurador de grande porte com sede na capital federal (A EMPRESA, 2009).

O grupo Caixa Seguros é constituído de 747 funcionários, 97 estagiários, e 316 prestadores de serviços, obteve um faturamento de $\mathrm{R} \$ 5.747$ milhões no ano de 2009 e apresentou um patrimônio líquido de $\mathrm{R} \$ 2.228,2$ milhões. Os ativos financeiros de curto e longo prazo sob gestão da empresa passaram de $R \$ 10.115,3$ milhões em 2007 para $\mathrm{R} \$ 16.812,5$ milhões em 2009. Em 2001, quando a CNP Assurances assumiu o controle acionário e, conseqüentemente, a gestão da empresa, o grupo apresentava um lucro líquido de $R \$ 96,9$ milhões e em 2009 a empresa fechou o seu balanço com lucro líquido de $R \$ 759,9$ milhões, ou seja, um crescimento de aproximadamente $785 \%$ desde o início da gestão da empresa francesa no Brasil (RELATÓRIO DE SUSTENTABILIDADE, 2009). 


\subsection{Participantes do Estudo}

O estudo realizado teve participação do Diretor de Operações da Caixa Seguros, José Lopes Coelho, brasileiro. Como Diretor Comercial da empresa nos anos de 1999 a 2001, foi um dos responsáveis pela preparação da empresa para a valorização e posterior venda da participação acionária até então detida pela FUNCEF - Fundação dos Economiários Federais para a CNP Assurances. É Diretor de Operações da Caixa Seguros desde 2002. Também teve a participação do Presidente da Caixa Seguros, Thierry Claudon, francês. Responsável pela análise do mercado brasileiro e prospecção de oportunidades para a CNP Assurances desde 1998 e atua como Presidente da Caixa Seguros desde a entrada da CNP Assurances no Brasil, em 2001. O estudo foi desenvolvido com a participação de apenas estes entrevistados, devido ao fato de terem sido os únicos envolvidos diretamente no processo de entrada da CNP Assurance no Brasil, objeto focalizado pelo estudo.

\subsection{Instrumentos de pesquisa e fonte de evidência}

Os instrumentos de pesquisa utilizados foram um roteiro de entrevista semiestruturado com os Diretores envolvidos diretamente no processo de entrada da empresa francesa no Brasil, havendo a diferença de roteiro para o líder brasileiro e francês, assim como roteiros de pesquisa documental e bibliográfica. $O$ roteiro de entrevista foi submetido à análise de especialistas no processo de internacionalização de empresas, antes de sua aplicação. As sugestões recebidas foram incorporadas na versão final.

Esta pesquisa utiliza fontes de evidência primárias - por meio das entrevistas - e secundárias - os documentos disponibilizados pela Caixa Seguros (RICHARDSON, 1999). Para o levantamento das informações secundárias foi realizada pesquisa de informações em jornais e revistas que tratam de negócios, principalmente para conseguir informações sobre as regulamentações presentes antes e depois de 2001 , 
ano de entrada da CNP Assurances no Brasil. Também foram levantados dados dos relatórios anuais da Caixa Seguros, material dos sites da Caixa Seguros e CNP Assurances.

\subsection{Procedimentos de coleta e análise de dados}

Yin (2005) recomenda utilizar diferentes técnicas de coleta de dados qualitativas, dentre elas a pesquisa documental e questionário. Assim, a utilização de diversas fontes de evidência permite desenvolver linhas convergentes de investigação direcionadas ao mesmo fato e observar diversos aspectos de uma mesma questão.

Assim, para obter fontes de evidência, foi realizada uma entrevista com o Presidente da Caixa Seguros no dia 17 de Dezembro de 2010, e com o Diretor de Operações no dia 05 de Janeiro de 2011, ambas nos seus respectivos escritórios. As entrevistas foram gravadas e tiveram duração de aproximadamente 50 minutos cada, sendo, posteriormente, transcritas para análise.

Outros dados de natureza qualitativa foram disponibilizados pelos referidos gestores e alguns coletados através do site da empresa Caixa Seguros e CNP Assurances.

A análise de dados partiu do ponto inicial, que é o estabelecimento de prioridades e os porquês (YIN, 2005). As prioridades do presente trabalho a partir da análise do contexto foram: entender o cenário da Caixa Seguros e as razões que culminaram com a entrada da empresa francesa como sua acionista; identificar as razões de interesse da entrada da CNP no mercado brasileiro; estabelecer comparações do modo de entrada com o Modelo de Uppsala e o Paradigma de OLI; e, por fim, comparar o modo de entrada com os principais meios de internacionalização de serviços financeiros, dentre eles os de seguros.

Para facilitar o processo de análise, e seguindo uma das estratégias analíticas de Yin (2005), realizou-se uma descrição do caso para ajudar a identificar as ligações causais apropriadas a serem realizadas. 


\section{RESULTADOS E DISCUSSÃO}

O objetivo deste tópico é apresentar os resultados da pesquisa, utilizando, primeiramente, a descrição da estrutura analítica e a sequência para tal análise. Em seguida, abordar-se-ão os resultados por subtópicos de forma a facilitar o entendimento do caso.

A partir das entrevistas realizadas com os diretores da Caixa Seguros, com o objetivo de identificar o processo de entrada e os fatores de consolidação da empresa francesa CNP Assurances no mercado brasileiro e a relação deste processo, confrontada com teorias sobre internacionalização de empresas e os resultados dos estudos anteriores no mesmo setor, permitiu-se identificar a trajetória de escolha e entrada da empresa francesa no Brasil. $E$ ainda, foram identificadas as razões que levaram os acionistas da Caixa Seguros a se interessarem em alienar o controle acionário da empresa para uma empresa estrangeira. Inicialmente será apresentado um breve histórico empresarial da Caixa Seguros para, em seguida, relatar as razões do interesse na alienação do seu controle acionário. Posteriormente o mesmo será realizado com a CNP Assurances: um histórico empresarial resumido e as razões de busca de um novo mercado. Finalmente, uma análise comparativa crítica confrontando os resultados auferidos com as principais teorias de internacionalização, estudos anteriores realizados sobre o setor de seguros e as decisões estratégicas envolvidas na entrada e consolidação no mercado brasileiro.

\subsection{Histórico Empresarial da Caixa Seguros}

Em 1967 foi criado, pela Caixa Econômica Federal (CEF), o Serviço de Assistência Social e Seguros dos economiários - SASSE. Dentre os serviços prestados aos funcionários da CEF havia também os de seguros, através da então seguradora de mesmo nome. Em 1978, o Governo Federal resolveu extinguir por lei o SASSE, incorporando os empregados da Caixa ao INSS. A Caixa resolveu criar um fundo de 
pensão fechado para complementação das aposentadorias de seus empregados, resultando na criação da FUNCEF- Fundação dos Economiários Federais, que herdou $51,75 \%$ das ações da SASSE seguros. Assim, 51\% das ações da SASSE ficaram com a FUNCEF, e o restante ficou com a CEF. Em seguida, entre 1995 e 1998 a Secretária de Previdência Complementar determinou que os fundos de pensão não poderiam deter mais que $20 \%$ em participação das empresas de seguros.

A partir dessa nova determinação, a FUNCEF foi obrigada a se adequar à nova norma. Assim sendo, contratou-se uma empresa de consultoria especializada para realização de estudos com vistas a encontrar a melhor alternativa: venda total de suas ações da Caixa Seguros ou a venda de apenas 31\% do total. Por orientação da consultoria contratada e da CEF, decidiram a venda total das ações para que pudessem valorizar mais a parte da FUNCEF e, em linha com as diretrizes do governo federal, aumentar a participação de empresas estrangeiras no Brasil.

No final da década de 1990 iniciou-se a preparação para a venda das ações, optando por um processo de concorrência internacional. Empresas de consultoria foram contratadas para modelar o processo de venda e buscarem por interessados fora do Brasil. Disponibilizaram aos interessados um data room com todas as informações e números da empresa. Nessa época o nome SASSE já tinha sido substituído para Caixa Seguros para dar mais visibilidade à empresa e atrelar o seu nome ao nome da Caixa Econômica Federal que, além de acionista oferece o seu balcão para a venda dos produtos da empresa de forma exclusiva, no modelo denominado no mercado de bancassurances. Essa mudança de nome ocorreu para valorizar ainda mais a empresa devido o nome Caixa ser uma referência nacional e muito valorizado.

Realizado todo o processo legal e burocrático, em fevereiro de 2001 ocorreu a licitação, quando a CNP Assurances venceu, logo na primeira etapa do processo, devido à alta proposta de compra das ações. As ações da Caixa Seguros foram tão valorizadas pela CNP que a proposta feita foi mais que $100 \%$ do valor de venda sugerido pela empresa de consultoria e aprovado pelo Conselho de Administração da seguradora. O valor mínimo estabelecido de venda à época foi de $R \$ 400$ milhões e a CNP realizou a proposta e pagou pelas ações um total de $R \$ 1,065$ bilhões. 
Em Julho de 2001 a CNP Assurances iniciou suas atividades na Caixa Seguros como acionista majoritário e responsável por toda a gestão da seguradora. Para tanto, manteve representação majoritária no Conselho de Administração, inclusive a sua presidência, além da prerrogativa de nomeação de toda a Diretoria Executiva da empresa. Essa decisão certamente foi importante pois eliminou por completo o risco de interferências políticas, comuns em organizações vinculadas às empresas estatais brasileiras, como a CEF, a qual passou a ter o direito de participar do Conselho de Administração, mas não o direito de interferir diretamente na gestão e contratação de empregados.

O processo de alteração da gestão da empresa, passando de uma espécie de gestão pública para gestão privada, foi apoiado por uma consultoria empresarial brasileira. Neste processo de mudança houve ampla reestruturação organizacional na empresa, com implementação de modernos sistemas de gestão, implementação de mecanismos de desempenho dos colaboradores, redução do quadro de empregados e contratação de empregados e gestores devidamente qualificados para as funções. Houve também elevados investimentos em novos sistemas de tecnologia da informação, na área de controle, conformidade, gestão de riscos, entre outros, além de investimentos em treinamentos para qualificação de profissionais na área de seguros, considerados escassos à época.

Toda a mudança na gestão da Caixa Seguros gerou um salto de produtividade e lucratividade ano após ano. De acordo com os dados disponibilizados pela empresa, do ano de 2000 a 2009,o faturamento da empresa foi de $21 \%$ a.a, enquanto que a média do faturamento do mercado de seguros foi de $14 \%$ a.a. Portanto, de $R \$$ 1.070 milhões em 2000 a Caixa Seguros obteve de faturamento de $R \$ 5.745$ milhões em 2009. O número total de funcionários na empresa no ano de 2000 era 829 e em 2009 totalizou 747, havendo uma queda de 10\% durante o período. As despesas administrativas em relação ao faturamento da empresa, para o período, recuaram de $7,9 \%$ para $3,3 \%$.

Para o ano de 2010 os resultados financeiros da empresa não puderam ser disponibilizados, pois não houve a publicação oficial ao mercado. No entanto, de acordo com as informações recebidas nas entrevistas, a empresa conseguiu manter a mesma média de produtividade e lucratividade. Em novembro de 2010 o Grupo Caixa Seguros estava em 6 lugar entre os maiores grupos seguradores do Brasil. 


\subsection{Entendimento das razões da CNP Assurance}

Em 1995, o atual presidente da Caixa Seguros, Thierry Claudon, viajou à Argentina visando a fazer uma parceria com empresas argentinas com o objetivo de conhecer e aprender mais sobre os fundos de pensões privadas que a Argentina havia lançado no Mercado. O objetivo era entender como funcionava para, em seguida, lançar o mesmo modelo na Europa. Este processo de entrada, inicialmente na Argentina, deveu-se ao fato de este país não possuir barreiras regulatórias e também a percepção francesa de que o mundo latino é mais fácil para negócios devido à cultura. Em 1995 já havia grandes seguradoras na Argentina devido à ausência de barreiras regulamentadoras. Assim, em 1995 a CNP Assurances estabeleceu duas empresas de seguro de vida através de associações com empresas argentinas.

Apenas a partir de 1998, Thierry iniciou as viagens ao Brasil para entender melhor o mercado e procurar por parcerias. O interesse de entrar no Brasil ocorreu apenas após as reformas regulamentares ocorridas no mercado brasileiro. Assim, poderiam entrar no Brasil com parcerias significativas possibilitando o controle e também enviarem os dividendos para a França.

A razão para a CNP Assurances procurar outros mercados, dentre eles o Brasil, foi principalmente devido à maturidade do mercado francês. A previdência privada com vendas em bancas de vendas é o principal negócio da CNP Assurances. O lucro da venda deste produto é baseado na taxa de juros do país. Na Europa, as taxas de juros SELIC estavam abaixo de 5\% a.a., e com perspectiva de redução, logo os rendimentos da CNP reduziriam ainda mais.

Enquanto isso, no Brasil a taxa de juros SELIC estava acima de $11 \%$ e com perspectivas de manter constante ou aumentar. A venda de previdência privada em bancos era um procedimento comum no mercado, ao contrário de muitos países. O Brasil estava com o mercado aberto para investimentos externos e muitas empresas brasileiras procuravam por parcerias estrangeiras, pois aumentava a credibilidade, trazia status e capital e, ainda, o crescimento econômico tendia a aumenta a demanda por seguros. Em resumo, avaliava-se que era um cenário perfeito para a entrada da CNP Assurances no Brasil. Assim sendo, necessitaria apenas 
estabelecer a parceria com uma empresa que assemelhava culturalmente com a CNP.

Por convite do governo brasileiro e da empresa de consultoria contratada, a CNP Assurances participou da licitação, em fevereiro de 2001, para a venda de 51,75\% das ações da Caixa Seguros. A decisão de entrar no mercado brasileiro já estava tomada. O perfil da Caixa Seguros, com venda de seus produtos através do balcão da CEF, assemelhava-se ao perfil de venda da CNP, e ainda, um dos principais produtos da Caixa Seguros era a previdência privada. A certeza de entrada no Brasil foi confirmada com o alto valor da proposta de compra das ações da Caixa Seguros, feita pela CNP, um pouco mais de duas vezes o valor mínimo, totalizando $R \$ 1,065$ bilhões. Este valor também era aproximadamente dez vezes maior que o patrimônio da Caixa Seguros na época.

É importante citar que no início de 2001, no cenário político brasileiro, já havia boatos e pesquisas sobre a possível candidatura do esquerdista Luiz Inácio Lula da Silva, o que para muitas empresas estrangeiras era visto como um risco alto. Pois, na visão destas, investir diretamente em uma empresa parcialmente governamental haveria a chance de re-estatização quando a esquerda tomasse posse em 2002. Para muitas, era um risco altíssimo que não justificava um alto valor de investimento. Porém, este cenário político brasileiro não assustava os franceses, pois a França, desde 1981, tem vivenciado a troca frequente entre direita e esquerda. Em 1981 a esquerda chegou ao poder pela primeira vez e, apesar de toda a ideologia, percebeu-se que a economia é quem dita as regras para as ações do governo, e não vice-versa.

Para a empresa francesa, a entrada no mercado brasileiro não representou grandes mudanças culturais. E para facilitar os negócios e o ambiente corporativo, optaram por qualificar os profissionais brasileiros ao invés de trazer profissionais franceses, pois gostam do jeito criativo, facilidade de mudança e adaptação dos brasileiros. Em contrapartida, encontram dificuldades com a falta de constância e fidelidade nos controles internos e também a cultura do brasileiro de não pensar no futuro, o que prejudica muito a venda de seguros de vida.

O maior choque no Brasil foi trabalhar com seguros de bens móveis e imóveis, pois nunca haviam trabalhado com este tipo de seguro anteriormente. E o seguro de bens móveis, como o carro, é o que o brasileiro mais busca adquirir. Contaram 
também com o conhecimento e experiência dos funcionários da CAIXA SEGUROS neste segmento.

Devido ao sucesso da operação de aquisição realizada, a sede da CNP Assurances já autorizou o plano de expansão da empresa para alguns países da América Latina e a expansão tem como base o Brasil.

\subsection{A Estratégias de Internacionalização da CNP Assurance}

Ao analisar a descrição e razões de entrada da CNP Assurance no Brasil e comparar com as Estratégias de Internacionalização de Ansoff e McDonnel (1993) podem-se identificar as principais estratégias tomadas para o processo de internacionalização.

A empresa utilizou-se de uma análise detalhada e ampla dos fatores econômicos, culturais e políticos (ANSOFF; MCDONNEL, 1993). O preparo da empresa para tal análise só foi possível pelas experiências anteriormente vividas pela empresa em seu ambiente doméstico, principalmente as crises econômicas e políticas vivenciadas pela empresa. O período de conhecimento aprofundado no mercado brasileiro iniciou-se desde a entrada na Argentina. A proximidade física e cultural entre os países contribuiu para um conhecimento mais sutil do mercado brasileiro pelos franceses, incluindo as percepções mais implícitas da área estratégica da empresa. A presença frequente do líder da internacionalização da CNP no Brasil desde 1998 é outro meio utilizado para aprofundar o conhecimento, conversas com outras empresas brasileiras do setor para uma possível parceria, que culminou com a entrada definitiva no Brasil, apenas em 2001.

Como o processo de internacionalização de uma empresa deve ir ao encontro dos seus objetivos, logo a análise de uma AEN deve ser baseada nos objetivos e critérios estratégicos da empresa a ser internacionalizada (ANSOFF; MCDONNEL, 1993). A escolha do Brasil como um mercado para esta entrada foi embasada, principalmente, no objetivo de equilibrar a carteira estratégica da empresa. Assim, a empresa buscava assegurar a rentabilidade e crescimento continuado em curto e longo prazo ao entrar em um país com uma taxa de juros muito maior que a do seu 
país, podendo assim ter maiores possibilidades de ganhos em cima dos produtos, um mercado com alto potencial de crescimento econômico e populacional, gerando ganhos de escala nos produtos, e ainda atuar em novos tipos de negócios como os seguros de bens móveis e imóveis.

A empresa francesa seguiu uma ordem de envolvimento progressivo para a internacionalização, e esta ordem assemelha-se, em partes, às etapas de realização de um envolvimento progressivo proposto por Ansoff e McDonnell (1993), como foi apresentada na seção 2.5. As estapas do envolvimento gradativo da CNP foram: a) inicialmente a formulação da estratégia de internacionalização com o objetivo de aumentar os rendimentos dos produtos e a identificação da América Latina com região geográfica promissora; b) em seguida a busca do Brasil como AEN que satisfazia a estratégia; c) logo depois a análise da cultura, riscos financeiros e políticos, perspectiva de crescimento e rentabilidade, estratégias mais eficientes de marketing, produto, e distribuição; d) posteriormente, a análise de entrada com a realização de uma parceria com uma empresa já fortemente atuante no mercado, facilitando a estratégia de competição no mercado brasileiro; e) por fim, a decisão de fixar permanentemente no mercado brasileiro devido à atratividade a um baixo custo.

\subsection{O modo de Entrada e as Teorias de Internacionalização}

Estudar o processo de internacionalização de uma empresa em geral, e neste caso uma empresa de serviços de seguros, focalizando apenas em uma das principais teorias de processos de internacionalização limitaria a compreensão geral de todo o processo envolvido. Por isto, para uma melhor análise do processo de entrada da CNP Assurances no Brasil, o presente trabalho comparou este processo com o Modelo de Uppsala e o Paradigma Eclético de OLI. 


\subsubsection{A entrada da CNP e o Modelo de Uppsala}

As etapas de envolvimento gradativo da CNP com o mercado brasileiro, ver 4.3, assemelham-se com as proposições dos principais autores da Escola de Uppsala (JOHANSON; VAHLNE, 1977, 2006; FORSGREN, 2002) ao citarem que aumentar o conhecimento do mercado de entrada gradualmente visa a diminuir as incertezas e distâncias psíquicas. Este conhecimento do mercado brasileiro pela CNP Assurances foi importante, pois deu base para as decisões de comprometimento da empresa. Contribuindo para identificar a demanda do mercado em curto e longo prazo, os canais de venda dos seguros, as condições de transferências de dividendos para a França e as diferenças e semelhanças culturais entre os países.

No entanto, não há relação com o Modelo Prognóstico básico de internacionalização proposto por Forsgren (2002) com os países iniciais de entrada da CNP Assurances que, em resumo, afirma que a internacionalização inicia-se em países de menor distância física e investimentos em poucos países, e só então que entrariam em outros mercados mais distantes fisicamente e em muitos mercados simultaneamente, pois já teriam o aprendizado de internacionalização. A CNP entrou na Argentina em 1995, o primeiro mercado externo a atuar diretamente, logo, muito distante fisicamente, embora a distância psíquica fosse avaliada como pequena devido às origens latinas dos dois paises.

\subsubsection{A entrada da CNP e Paradigma Eclético de OLI}

No Paradigma Eclético de OLI, ver 2.1.2, um investimento externo direto em um processo de internacionalização baseia-se nas vantagens de propriedade, localização e internalização (DUNNING, 1980). As vantagens identificadas pela CNP foram:

- Propriedade: conhecimentos empreendedores e retornos de escala.

- Localização: altas taxas de juros, perspectivas de crescimento e rentabilidade. 
- Internalização: parceria com uma empresa com credibilidade no mercado brasileiro, mesmo modelo de negócio e aprendizado em um novo negócio como o seguro de bens móveis e imóveis.

Como disponibilidade de net ownership advantages (vantagens de atuar em mercados desconhecidos), pode-se citar a experiência e conhecimento do mercado de seguros (DUNNING, 1980, 2008).

\subsection{A Internacionalização de serviços e o modo de entrada da CNP}

Sobre os processos de internacionalização de serviços propostas pelos autores do tema, ver 2.2 (CONTRACTOR; KUNDU; HSU, 2002; BLOMSTERMO; SHARMA, 2006; JOHANSON; VAHLNE, 2006; PEINADO; BARBER, 2006), observamos que a aquisição do controle acionário da Caixa Seguros pela CNP foi de forma a garantir que esta tivesse o controle da empresa, logo realizando as alterações na gestão empresarial para garantir maior market share. O modo de entrada de serviços em um mercado estrangeiro é crucial e relaciona-se com o controle considerado necessário. O controle contribui para o alcance dos objetivos da organização no mercado, pois este controle permitirá a qualidade e pontualidade para os clientes, garantindo o nome da empresa no mercado doméstico e estrangeiro.

Como o serviço de seguros situa-se no subgrupo de serviços em conhecimento intensivo, segundo Peinado e Barber (2006), o modo de entrada da CNP está de acordo com a teoria de entrada deste subgrupo. Pois este entrou no mercado utilizando maior controle das operações, o que para este é devido ao baixo investimento necessário para iniciar as operações e a dificuldade de transferência de conhecimento tácito, em relação ao serviço de capital intensivo. As razões de entrada da empresa francesa é, como o autor propõe em seu estudo, a entrada dos serviços de conhecimento intensivo em outros mercados e está condicionada mais pelas oportunidades competitivas do país estrangeiro do que pela estabilidade econômica e política de países com culturas similares ao país de origem, como foi evidenciado na entrevista com o diretor francês da CNP. 


\subsection{O Modo de entrada da CNP e a Internacionalização de Serviços Financeiros e Seguros}

O processo de internacionalização de serviços financeiros de acordo com os estudos para este setor, ver 2.3, é um processo que depende de diferentes e complementares reformas regulamentares (CONTRERAS; YIN, 2003). Reformas que promovam a liberalização do mercado, reforma das regulamentações financeiras, e a eliminação do fluxo de capitais além-fronteiras.

As reformas regulamentares no Brasil buscaram não provocar a instabilidade do mercado, nem o fluxo de capitais voláteis, um dos maiores impedimentos da abertura de mercados em países em desenvolvimento (CONTRERAS; YIN, 2003). Dentre os benefícios ao Brasil com a entrada da CNP Assurances, podem-se citar o uso de maiores tecnologias no setor, globalização, aumento da performance financeira e o aumento de eficiência.

O meio usado pela CNP Assurances para entrar no mercado brasileiro está de acordo com o mais usado pelo setor financeiro em todo o mundo, fusões e aquisições. Tem sido o meio mais usado para a expansão além-fronteiras de serviços financeiros na busca de diminuir o risco e as barreiras presentes nos países de entrada. A CNP Assurances possui como razão o potencial de lucro do mercado brasileiro. Não houve a entrada no Brasil para seguir algum grande cliente.

As características do mercado brasileiro, em 2001, não se assemelhavam às características mais prováveis de expansão de uma empresa de seguros proposta por Focarelli e Pozzolo (2008), ver 2.4. O Brasil não é próximo geograficamente da França, não possuía sistemas de telecomunicações mais desenvolvidos, nem um ambiente jurídico eficiente e tampouco um maior nível de educação. No entanto, tem mercado de grandes proporções.

O PIB per capita da França é maior que o PIB per capita do Brasil, logo vai ao encontro dos estudos de Focarelli e Pozzolo (2008), que afirmam estar as companhias de seguros mais dispostas a internacionalizarem suas operações através de fusões e aquisições, se estas vierem de países que possuem PIB per 
capita maior que o país de destino e ainda que possuam maior penetração de empresas de seguros. 


\section{CONCLUSÕES E RECOMENDAÇÕES}

O processo de entrada da CNP Assurances no Brasil foi realizado buscando formas de diminuir o risco de entrada em um novo mercado, a aquisição do controle acionário da Caixa Seguros contribuiu para que a empresa continuasse atuando com sua expertise em previdência privada, e aumentar o conhecimento com a atuação em seguros de bens, um novo negócio para a CNP, porém de conhecimento da Caixa Seguros. Este processo usado pela CNP para entrar no mercado brasileiro é o mesmo processo de entrada que empresas do mesmo setor de todo o mundo têm usado para internacionalização de seus negócios.

O fator de entrada no mercado brasileiro, com a análise do modelo de OLI, deve-se principalmente para a vantagem de localização (DUNNING, 1980, 2008). Os franceses enxergaram no Brasil a possibilidade de aumentar seus rendimentos e a alta demanda de seguros no mercado brasileiro. A desregulamentação do mercado financeiro contribuiu para a consolidação da entrada da empresa francesa no Brasil. E ainda, usando desta vantagem, os próximos investimentos nos países Latino Americanos partirão exatamente do Brasil.

Para diminuir as incertezas e desafios encontrados no Brasil, a CNP utilizou-se de diversas estratégias de internacionalização e também, em partes, conforme a proposição do Modelo de Uppsala (JOHANSON; VAHLNE, 1977; FORSGREN, 2002). Ou seja, iniciaram um processo de conhecimento progressivo do mercado, buscando evidências sutis através de presenças mais constantes no Brasil e aproveitando a proximidade geográfica e cultural na Argentina. Esta presença, inicialmente na Argentina e só então no Brasil, serviu de experiência para, em seguida, poder ser usada no processo de entrada no Brasil e, futuramente, outros países da região.

Após entender todo o processo e as razões de entrada da CNP Assurances, observam-se que o Modelo de Uppsala e o Paradigma Eclético de OLI são complementares para facilitar o entendimento e as razões que motivaram a entrada no Brasil. Se a análise limitasse à apenas algum destes modelos de 
internacionalização, faltaria algo para complementar a compreensão de todo o processo.

A consolidação e o crescimento no mercado brasileiro foram realizados por meio de muitos investimentos educacionais para profissionalizar os funcionários da Caixa Seguros, investimentos na qualidade de vida e saúde de seus funcionários, estratégias agressivas de conquistas de market share, inicialização de um novo negócio na empresa, a Caixa Consórcios, análises constantes de mercado e suas perspectivas, maior desenvolvimento tecnológico dos seus sistemas de controles, controles de fraudes mais eficientes, planejamento estratégico e planos de ação de curto e longo prazo, e o acompanhamento e controle das metas estabelecidas.

O modelo de crescimento da Caixa Seguros tem se mostrado bastante eficiente, pois os resultados financeiros crescem cada vez mais a cada ano. De acordo com os dados de 2009, está em 5 a lugar no mercado (sem saúde), possuem 9 milhões de clientes e $R \$ 6$ bilhões de faturamento com 747 profissionais. Os ramos de atuação da empresa são: seguros, capitalização, vida e previdência e consórcios.

O sucesso de atuação dos franceses no mercado brasileiro, juntamente com a Caixa Seguros, proporcionou a autorização, pela matriz francesa, de investimentos de expansão para outros mercados na América Latina, expansões que partirão do Brasil.

$\mathrm{Na}$ análise deste estudo de caso foi possível identificar e descrever as razões de entrada da empresa francesa no mercado brasileiro, o processo de entrada, as vantagens para o mercado brasileiro, as estratégias de internacionalização e consolidação no mercado brasileiro e como se relacionam com os principais estudos de estratégias e processos de internacionalização. Por ser um estudo de caso, o objetivo deste trabalho foi tratar de uma generalização teórica, pois como aponta Yin (2005), "os estudos de caso são apenas uma ferramenta exploratória preliminar e não podem ser utilizados para descrever ou testar proposições". Apesar de este trabalho ter como fonte principal de informações dois participantes, estes foram peças chave na operação de aquisição pela CNP da empresa brasileira, e buscouse triangulação dos dados para garantir sua confiabilidade, comparando as entrevistas realizadas individualmente, e examinando fontes de informação secundárias. 
A entrada de serviços financeiros em geral no mercado brasileiro é um processo que está acontecendo desde 1996, por interesses diversos, mas que necessita de mais estudo e informações, por ser um fenômeno relativamente novo e de poucas referências. Propõe-se, portanto, que se estude a internacionalização de serviços financeiros em mercados em desenvolvimento e a continuidade do estudo para que se possam verificar os processos de entrada da mesma empresa nos mercados latino-americanos partindo do Brasil.

Além disso, será interessante para o estudo de internacionalização de serviços financeiros verificar como foram os processos de entrada e razões de outras empresas do mesmo setor no Brasil, e de onde vieram estas empresas. Assim, haverá mais estudos para facilitar o entendimento dos porquês de empresas de países desenvolvidos entrarem em mercados em desenvolvimento e quais teorias de internacionalização mais se encaixam.

Seria interessante, também, investigar como as empresas adquirem conhecimento do mercado brasileiro antes de sua entrada, qual o cenário econômico, cultural e político vivenciam e como estas vivências influenciaram na escolha do mercado para entrarem (ANSOFF; MCDONNEL, 1993). Espera-se que este trabalho incentive estudos sobre a internacionalização de serviços financeiros, principalmente de seguros, e como as empresas em geral devem buscar conhecimento para uma expansão além-fronteira. 


\section{REFERÊNCIAS}

A EMPRESA. CAIXA SEGUROS, 2009. Disponível em: < http://www.caixaseguros.com.br/portal/site/CaixaSeguros/menuitem.9b0da7952f61a 59b6cd4ac1230e001ca/?vgnextoid=1d677c16791c1110VgnVCM100000790110acR CRD\&menu=Quem+Somos\&submenu=A+empresa>. Acesso em: 22 nov. 2010.

ANSOFF, H. I. ;MCDONNELL, E. J. Implantando a administração estratégica. 2 $2^{a}$ edição. São Paulo: Atlas, 1993.

Bank for International Settlements. "The Banking Industry in the Emerging Market Economies: Competition, Consolidation, and Systemic Stability." - BIS Papers 4, August, 2001.

BECK, T.; WEBB, L., Economic, demografic, and institutional determinants of life insurance consumption across countries. World Bank, 2002.

BLOMSTERMO, A.; SHARMA, D. D. Choice of foreign market entry mode in service firms. International Marketing Review, v. 23, n. 2, pp. 211-229, 2006.

BODDEWYN, J. J.; HALBRICH, M. B.; PERRY, A.C. Service Multinationals: conceptualization, measurement and theory. Journal of International Business Studies, v. 17, n. 3, pp. 41-57, 1986.

BRASIL. Produto Interno Bruto, 2009. Disponível em: <http://www.indexmundi.com/pt/brasil/produto_interno_bruto_(pib).html>. Acesso em: 21 nov. 2010.

CONTRACTOR, F. J.; KUNDU, S. K.; HSU, C. C. A three-stage theory of international expansion: the link between multinationality and performance in the service sector. Journal of International Business Studies, v. 34, n. 1, pp 5-18, 2003.

CONTRERAS, P.; YI, S.; Internationalization of financial services in Asia-Pacific and the Werstern Hemisphere. In: 2nd annual conference in Hua Hin, Thailand on July 89, 2003. pp. 1-39. 
CUMMINS, J. D.; VENARD, B.; Insurance market dynamics: between global developments and local contingencies. Risk Management and Insurance Review, v. 11, n. 2, pp 295-326, 2008.

DUNNING, J. H. Toward an eclectic theory of international production: some empirical tests. Journal of International Business Studies, v. 11, n. 1, pp 9-31, 1980.

DUNNING, J. H.; LUNDAN, S. M. Institutions and the OLI paradigm of the multinational enterprise. Asia Pacific Journal Manage, v. 25, pp. 573-593, 2008.

FARIA, L. V.; Perspectivas do Mercado de seguros. Revista Brasileira de Risco e Seguro, v. 1, n. 1, pp 32-63, 2005.

FOCARELLI, D.; POZZOLO, A. F. Cross-border M\&As in the financial sector: Is banking different from insurance? Journal of Banking \& Finance, v. 32, pp. 15-29, 2008.

FORSGREN, Mats. The concept of learning in the Uppsala internationalization process model: a critical review. International Business Review, v. 11, n. 3, pp. 257-277, 2002.

HELLMAN, P. The Internationalization of finnish financial service companies. International Business Review, v. 5, n. 2, pp. 191-208, 1994.

HILAL, A.; HEMAIS, C. A. O processo de internacionalização na ótica da Escola Nórdica: evidências empíricas em empresas brasileiras. RAC, v. 7, n. 1, pp. 109-124, 2003.

HISTÓRIA DO SEGURO. Fenaseg, 2010. Disponível em: http://www.fenaseg.org.br/main.asp?TeamID=\{39CB7CD8-F7B8-4BC8-835D2F43B4ACBF4B\}. Acesso em: 17 jan. 2011.

JAVALGI, R. G.; GRIFFITH, D. A.; WHITE, D. S. An empirical examination of factors influencing the internationalization of service firms. Journal of Service Marketing, v. 17, n. 2, pp. 185-2001, 2003.

JOHANSON, J.; VAHLNE, J. E. Commitment and opportunity development in the internationalization process: a note on the Uppsala internationalization process model. Management International Review, v. 46, n. 2, pp. 165-178, 2006. 
JOHANSON, J.; VAHLNE, J.E. The internationalization process of the firm: a model of knowledge development and increasing foreign market commitments. Journal of International Business Studies, v. 8, n. 1, pp. 23-32, 1977.

KOGUT, B. Designing global strategies: profiting from operational flexibility. Sloan Management Review, v. 26, pp. 27-38, 1985.

KUMAR, M. S. Growth, acquisition and investment: an analysis of the growth of industrial firms and their overseas activities. Cambridge University Press, 1984.

LITAN, R., E.; MASSON, P.; POMERLEANO, M. Open Doors: foreign participation in financial systems in developing countries. Brookings Institutions Press, New York City, 2001.

MILLET, M. M. Brazil: Latin America's Largest Insurance Market Slows With Global Economic Downturn, But Continues To Grow With Positive Signs For The Future Mondaq, jan. 2010. Mondaq, Disponível em: < http://www.mondaq.com/article.asp? articleid=91984>. Acesso em: 20 nov. 2010.

NICOLÓ, G. D.; BARTHOLOMEW, P.; ZAMAN, J.; ZEPHIRIN, M. Bank consolidation, internationalization and conglomeration: trends and implications for financial risk. Financial Markets, Institutions and Instruments, v.13, n. 4, pp. 173217, 2004.

OUTREVILLE, J. F. Foreign affiliates of the largest insurance groups: locationspecific-advantages. The Journal of Risk and Insurance, v. 75, n. 2, pp. 463-491, 2008.

PAIVA, E. L.; HEXSEL, A. E. Contribuição da gestão de operações para a internacionalização de empresas. RAC, v. 9, n. 4, pp. 73-95, 2005.

PEINADO, E.; BARBER, J. A multidimensional concept of uncertainty and its influence on the entry mode choice: an empirical analysis in the service sector. International Business Review, v. 15, n. 3, pp. 215-232, 2006.

PERFIL CORPORATIVO. Perfil corporativo e histórico, 2010. Disponível em: <http://www.sulamerica.com.br/ri>. Acesso em: 17 jan. 2011.

RELATÓRIO DE SUSTENTABILIDADE, 2009. Disponível em: < http://www.caixaseguros.com.br/Corporativo/Publicidade/RelatorioAnual/pt/index.htm I>. Acesso em: 23 nov. 2010. 
REZENDE, S. F.; VERSIANI, A. F. Em direção a uma tipologia de processos de internacionalização. RAE, v.50, n. 1, pp. 24-36, 2009.

RICHARDSON, Roberto J. Pesquisa Social: Métodos e Técnicas. São Paulo: Editora Atlas, 1999.

VERGARA, S. C. Métodos de Pesquisa em Administração. São Paulo: Atlas, 2005.

WORLD BANK. Global development finance: charting a global recovery. Washington, 2009.

YIN, R. K. Estudo de Caso: planejamento e métodos. Porto Alegre: Bookman, 2005. 


\section{APÊNDICES}

\section{Apêndice A - Principais Prêmios e Reconhecimento do grupo CAIXA SEGUROS}

\begin{tabular}{|c|c|}
\hline Prêmios & Reconhecimento \\
\hline $\begin{array}{l}\text { Eleita a maior seguradora do País em } \\
\text { "Destaque de Vendas" no ramo de } \\
\text { Crédito. Prêmio Segurador Brasil }\end{array}$ & $\begin{array}{l}\text { Maior seguradora do Brasil em } \\
\text { aplicações, rentabilidade e patrimônio } \\
\text { líquido. Segunda maior em lucro líquido } \\
\text { e a terceira maior em lucro operacional } \\
\text { De acordo com o anuário Valor } 1000 \\
\text { Maiores Empresas apud Relatório de } \\
\text { Sustentabilidade } 2009 \text {. }\end{array}$ \\
\hline $\begin{array}{l}\text { Eleita o maior grupo segurador do Brasil } \\
\text { no quesito "patrimônio líquido ajustado". } \\
\text { Prêmio Conjuntura Econômica da FGV }\end{array}$ & $\begin{array}{l}\text { Décima seguradora mais admirada do } \\
\text { Brasil na avaliação de executivos do } \\
\text { setor. "As empresas mais admiradas do } \\
\text { Brasil", anuário especial da Carta } \\
\text { Capital. }\end{array}$ \\
\hline $\begin{array}{l}\text { Vencedor da categoria "Destaque", } \\
\text { prêmio que homenageia as } \\
\text { personalidades e empresas dos setores } \\
\text { de tecnologia e finanças que mais se } \\
\text { destacam no país. Devido ao acesso } \\
\text { instantâneo dos atendentes da Central } \\
\text { de Relacionamento às gravações e aos } \\
\text { feedbacks registrados. }\end{array}$ & $\begin{array}{l}\text { Eleita a 15a maior seguradora por venda } \\
\text { do Brasil pela publicação especial } \\
\text { "Exame Melhores e Maiores". O ranking } \\
\text { foi elaborado com base na avaliação dos } \\
\text { dados de mais de } 3500 \text { empresas, e dos } \\
\text { grupos privados do país }\end{array}$ \\
\hline Prêmio E-insurance 2009, pelo projeto & 76 maior grupo empresarial do Brasil na \\
\hline
\end{tabular}




\begin{tabular}{|l|l|l|}
\hline $\begin{array}{l}\text { Integração SOA-SAP } \\
\text { Seguros. } \\
\text { Financeiros. }\end{array}$ & $\begin{array}{r}\text { Sistemas de } \\
\text { Executivos }\end{array}$ & $\begin{array}{l}\text { classificação do anuário Valor Grandes } \\
\text { Grupos. }\end{array}$ \\
\hline & $\begin{array}{l}346^{\circ} \text { colocada no ranking das } 500 \\
\text { melhores empresas do Brasil, } \\
\text { considerando todos os setores da } \\
\text { economia, na avaliação da revista "As } \\
\text { Melhores do Dinheiro". }\end{array}$ \\
\hline $\begin{array}{l}\text { Controle da quantidade de gases dos } \\
\text { efeito estufa liberados por toda a } \\
\text { companhia. Com programas de redução } \\
\text { e plantio de árvores para compensar as } \\
\text { emissões. Em 2009 foram emitidos } 2 \text { mil } \\
\text { toneladas de co2, que foram } \\
\text { compensados com o plantio de 1.408 } \\
\text { árvores. }\end{array}$ \\
\hline
\end{tabular}

Quadro 2: prêmios e reconhecimento do grupo CAIXA SEGUROS Fonte: adaptado Relatório de Sustentabilidade 2009 <http://www.caixaseguros.com.br/Corporativo/Publicidade/RelatorioAnual/pt/index.html>

\section{Apêndice B - Roteiro de entrevista semi-estruturado}

\section{Diretor de Operações - José Coelho}

a) Há quanto tempo trabalha no grupo CAIXA SEGUROS?

b) Como foi sua participação no processo de entrada da CNP Assurance?

c) Quais foram os conhecimentos necessários que contribuíram para a entrada da CNP Assurance no grupo Caixa Seguros?

d) Quais os desafios, da época, para a entrada da CNP Assurance?

e) Que fatores levaram para haver a participação de outra empresa no grupo?

f) Houve outras empresas interessadas em entrar no grupo?

g) Como foi o processo de escolha destas empresas? (se houver)

h) Quais têm sido os desafios do grupo após a entrada da empresa francesa? 
i) Houve ou ainda há divergências culturais dentro da empresa?

j) Como o grupo trabalhou para diminuir a distância cultural entre Brasil e França no ambiente corporativo?

k) Já participou de algum processo similar anteriormente?

I) Quais as vantagens e desvantagens que identifica para o grupo após a entrada da CNP Assurance?

m) Há algo mais que acha importante acrescentar para entendermos melhor este processo de entrada?

\section{Presidente - Thierry Claudon}

a) Há quanto tempo está no Brasil?

b) Há quanto tempo trabalha para a CNP Assurance?

c) Qual foi o seu papel para a entrada da CNP Assurance?

d) Quais os fatores que levaram à escolha do Brasil e não outros países?

e) $\mathrm{Na}$ época da expansão, houve muitas regulamentações como barreiras de entrada? Quais?

f) Quais eram as maiores incertezas para a entrada no Brasil?

g) Quais foram e tem sido os maiores desafios de operar no Brasil?

h) Houve ou há muitas divergências culturais?

i) Como tem sido o trabalho para diminuir as divergências culturais da empresa?

j) Em quais países a CNP Assurance já atuava anteriormente no Brasil?

k) Como utilizaram destas experiências anteriores para a expansão para o Brasil?

I) Quais dos conhecimentos adquiridos nas expansões anteriores foram aproveitados para a expansão para o Brasil?

m) Já trabalhou de algum processo similar anteriormente?

n) Quais as vantagens e desvantagens que identifica para a CNP Assurances após a parceria com o grupo CAIXA SEGUROS? 


\section{ANEXOS}

\section{Anexo A - Organograma do Grupo CAIXA SEGUROS}

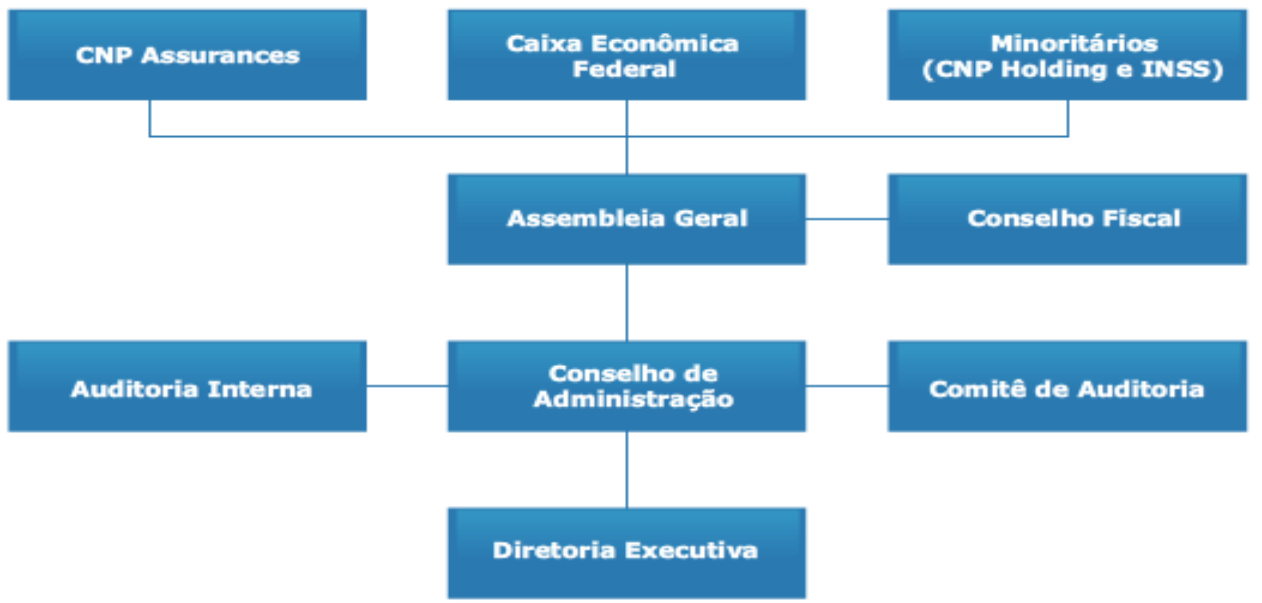

Figura 2: Organograma do Grupo CAIXA SEGUROS

Fonte: $<$ http://www.caixaseguros.com.br/Corporativo/Publicidade/RelatorioAnual/pt/conselho.html>

\section{Anexo B - Resultados Financeiros do Grupo CAIXA SEGUROS}

\section{Faturamento do Mercado*}

Evoluçăo entre 2000 e 2009 (R\$ Bilhões)

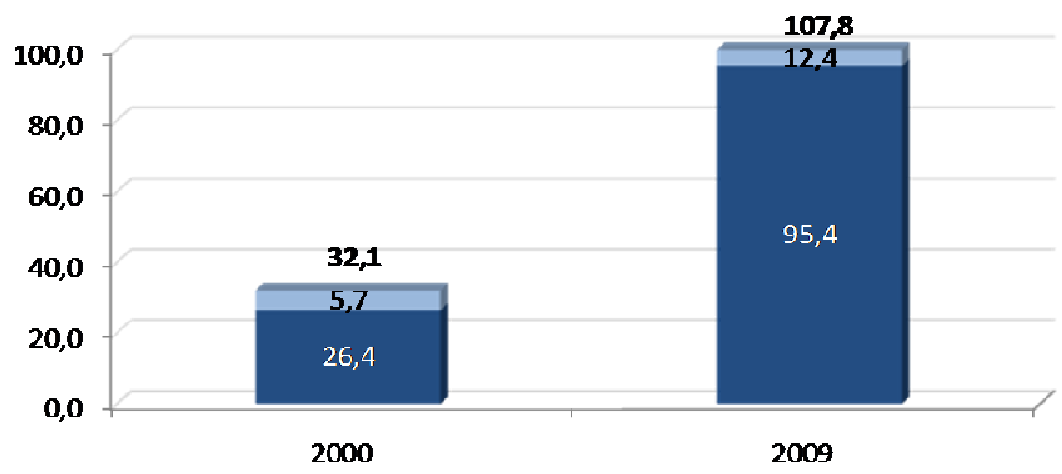

Figura 3: Faturamento do Mercado Fonte: CAIXA SEGUROS 
Faturamento do Grupo Caixa Seguros*

Evolução entre 2000 e 2009 (R\$ Milhões)

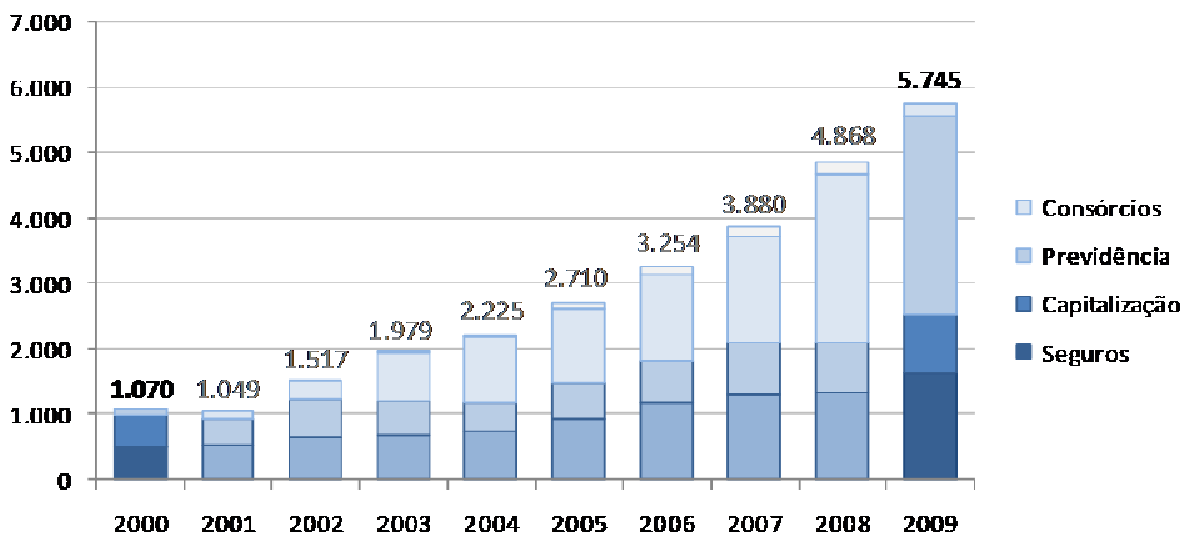

Figura 4: Faturamento do Grupo Caixa Seguros Fonte: CAIXA SEGUROS

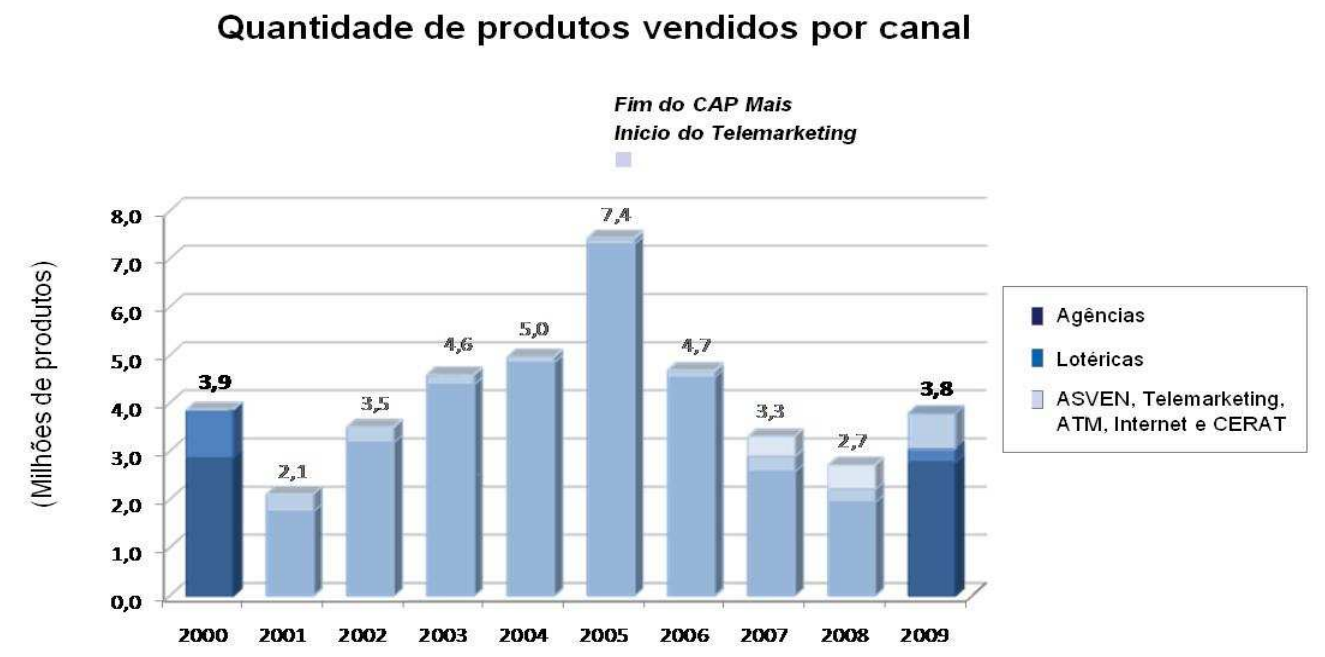

Figura 5: Quantidade de produtos vendidos por canal Fonte: CAIXA SEGUROS 


\section{Número de funcionários}

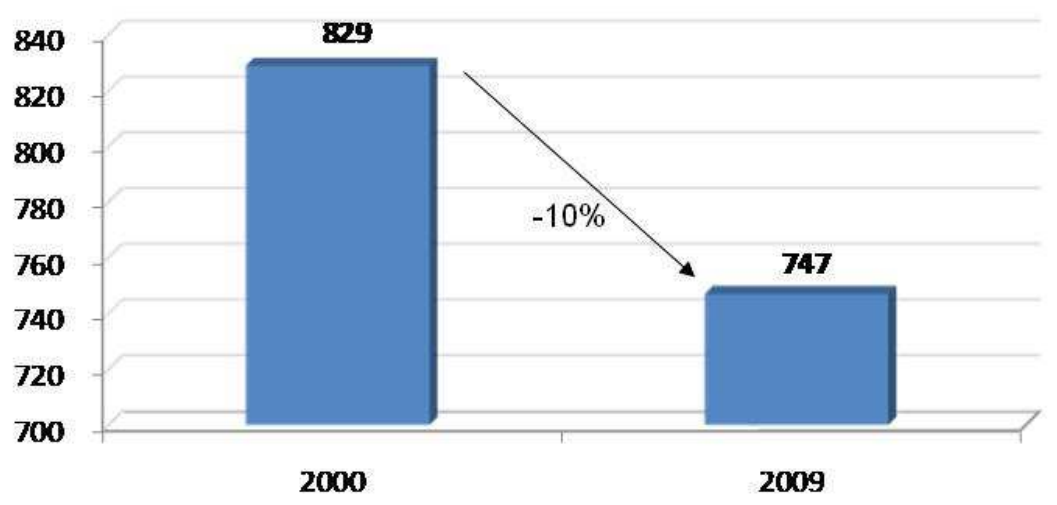

Figura 6: Número de funcionários

Fonte: CAIXA SEGUROS

\section{DA do Grupo Caixa Seguros}

(em \% do Faturamento)

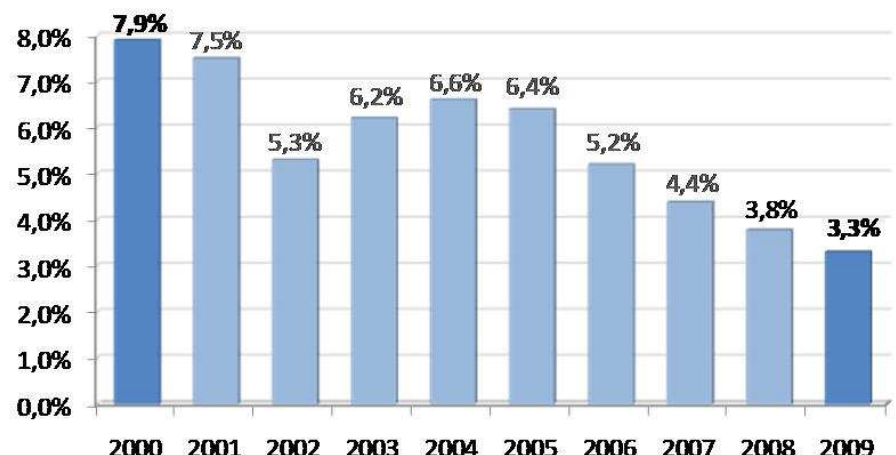

Figura 7: Despesa Administrativa do Grupo Caixa Seguros Fonte: CAIXA SEGUROS 
Margem técnica do Grupo Caixa Seguros

(em R\$ Milhões)

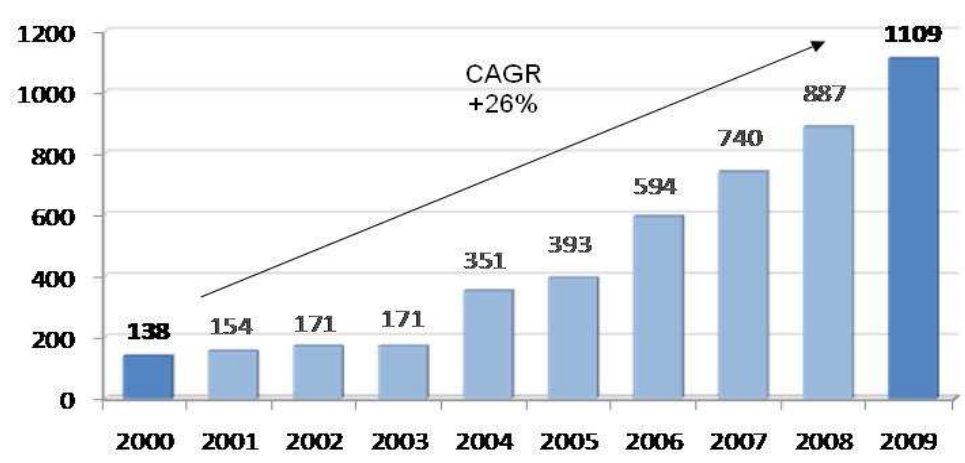

Figura 8: Margem técnica do Grupo Caixa Seguros Fonte: CAIXA SEGUROS

Resultado financeiro do Grupo Caixa Seguros (em R\$ Milhões)

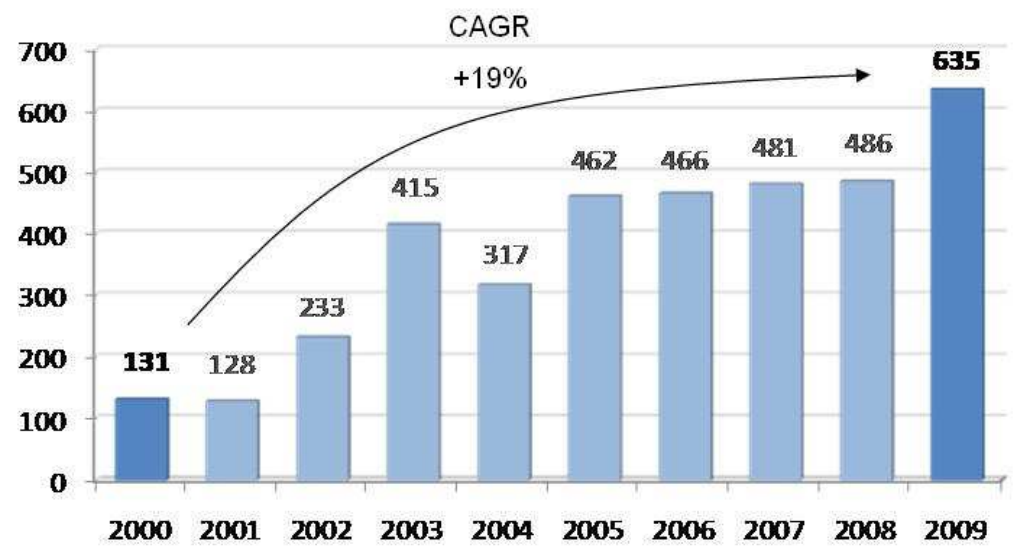

Figura 9: Resultado financeiro do Grupo Caixa Seguros Fonte: CAIXA SEGUROS 
Despesas com impostos do Grupo Caixa Seguros (em R\$ Milhões)

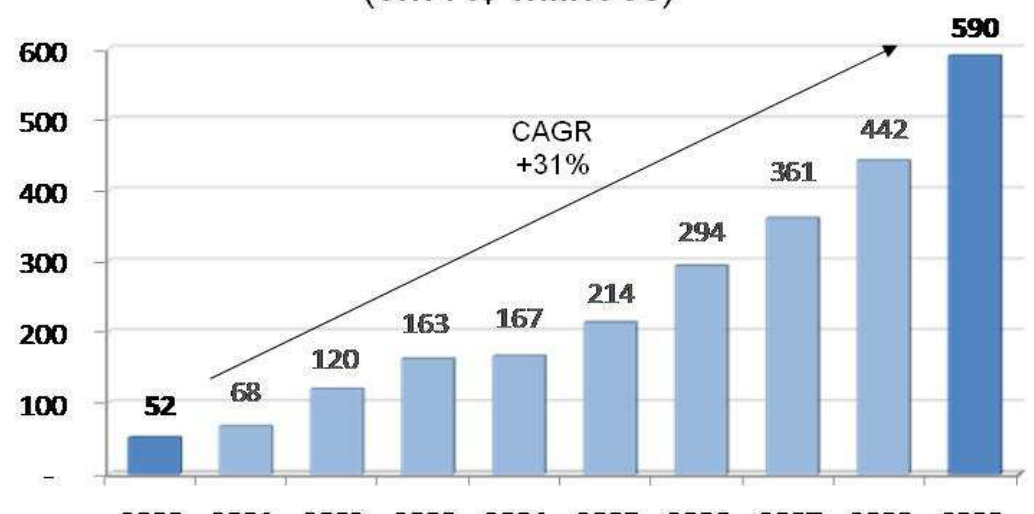

$\begin{array}{llllllllll}2000 & 2001 & 2002 & 2003 & 2004 & 2005 & 2006 & 2007 & 2008 & 2009\end{array}$

Figura 10: Despesas com impostos do Grupo Caixa Seguros Fonte: CAIXA SEGUROS

\section{Resultado líquido do Grupo Caixa Seguros (em R\$ Milhões)}

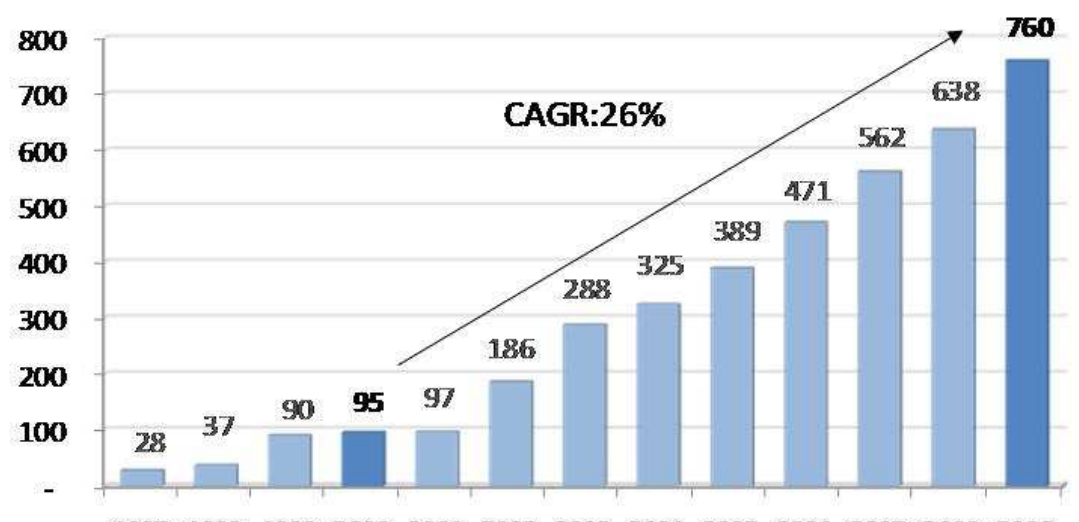

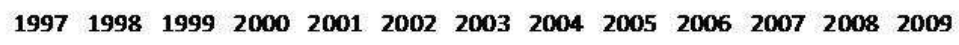
Figura 11: Resultado líquido do Grupo Caixa Seguros Fonte: CAIXA SEGUROS 
Retorno sobre património líquido

(ROE)

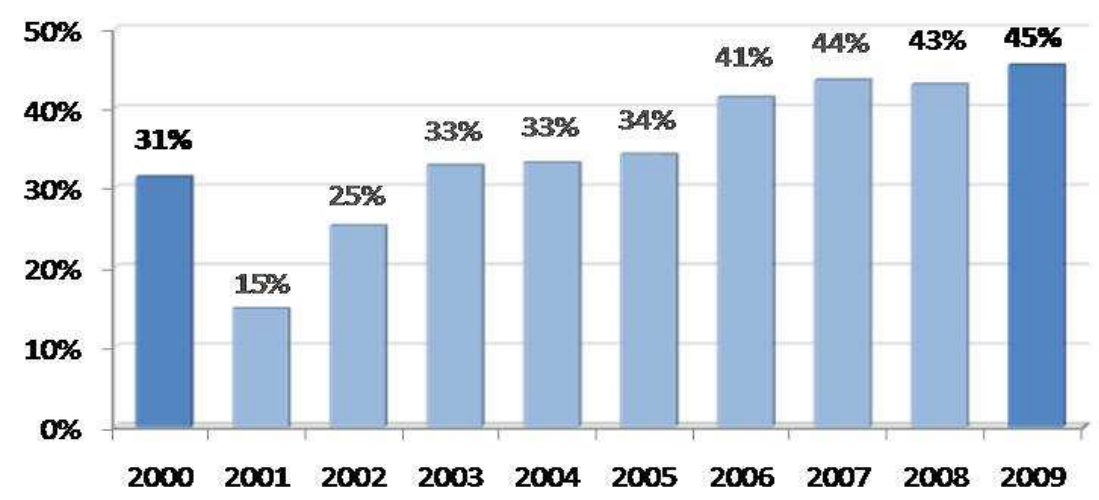

Figura 12: Retorno sobre o patrimônio líquido Fonte: CAIXA SEGUROS

Patrimônio líquido do Grupo Caixa Seguros (em R\$ Milhões)

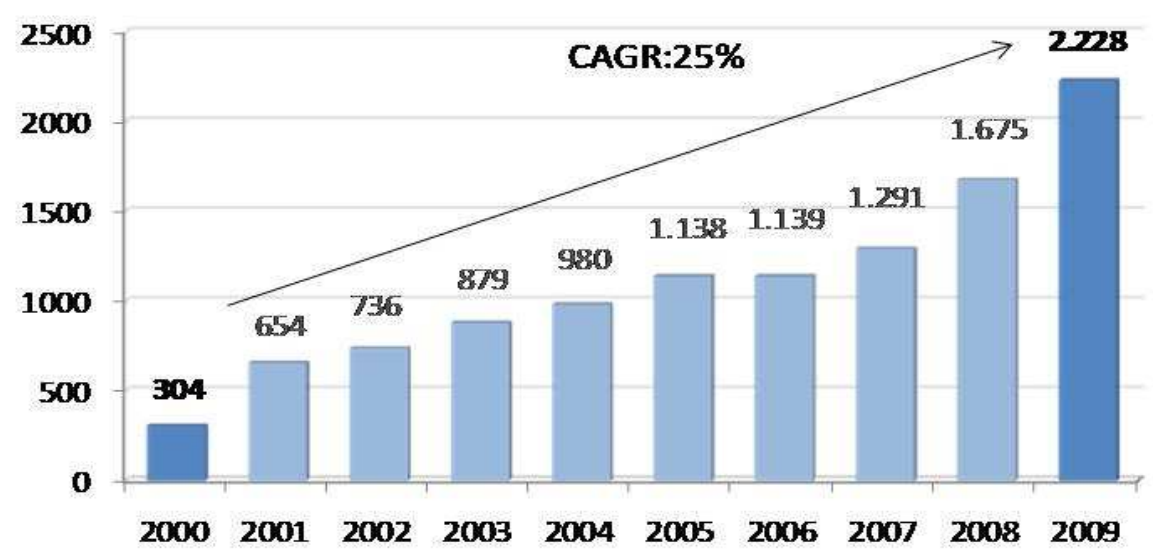

Figura 13: Patrimônio líquido do Grupo Caixa Seguros Fonte: CAIXA SEGUROS 
Ativos sob gestão do Grupo Caixa Seguros

(em R\$ Milhões)

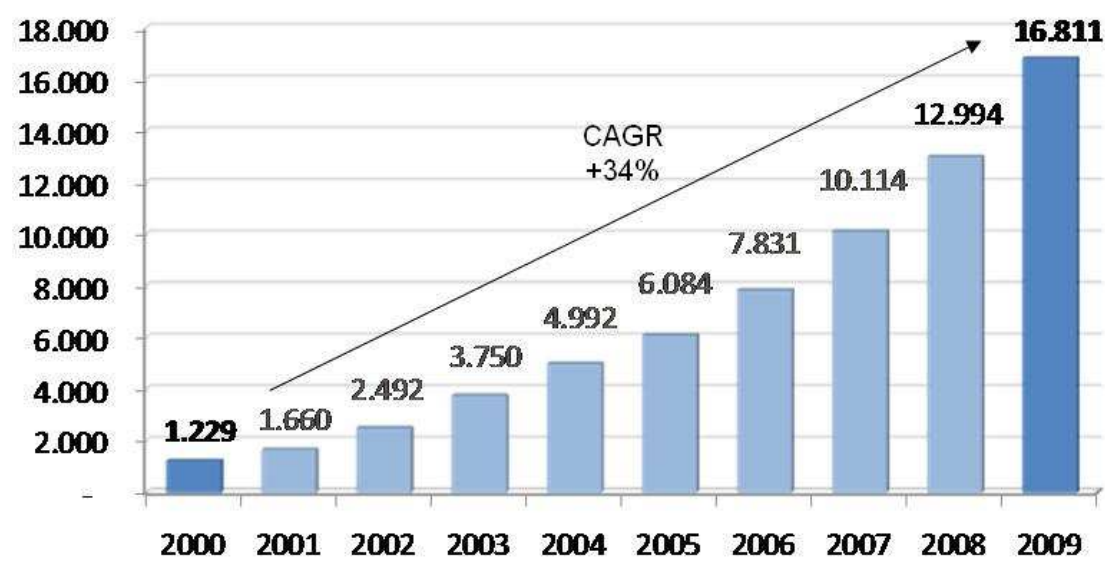

Figura 14: Ativos sob gestão do Grupo Caixa Seguros Fonte: CAIXA SEGUROS

\section{Margem de Solvência do Grupo Caixa Seguros}

Evolução entre 2000 e 2009*

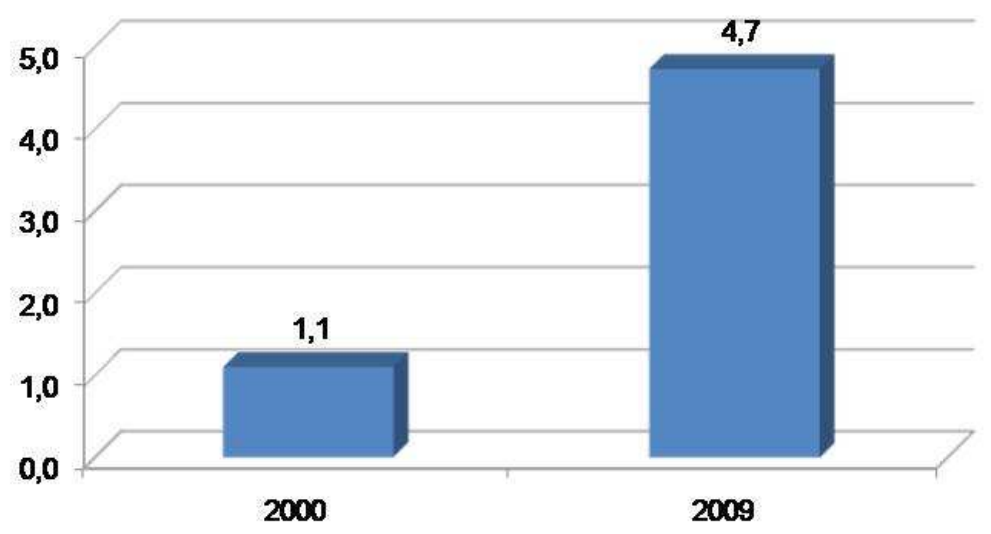

Figura 15: Margem de solvência do Grupo Caixa Seguros Fonte: CAIXA SEGUROS 